NASA/TM-2007-214473

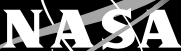

\title{
Application of Carbon Based Nano-Materials to Aeronautics and Space Lubrication
}

Kenneth W. Street, Jr., and Kazuhisa Miyoshi

Glenn Research Center, Cleveland, Ohio

Randy L. Vander Wal

The Universities Space Research Association, Cleveland, Ohio 


\section{NASA STI Program . . . in Profile}

Since its founding, NASA has been dedicated to the advancement of aeronautics and space science. The NASA Scientific and Technical Information (STI) program plays a key part in helping NASA maintain this important role.

The NASA STI Program operates under the auspices of the Agency Chief Information Officer. It collects, organizes, provides for archiving, and disseminates NASA's STI. The NASA STI program provides access to the NASA Aeronautics and Space Database and its public interface, the NASA Technical Reports Server, thus providing one of the largest collections of aeronautical and space science STI in the world. Results are published in both non-NASA channels and by NASA in the NASA STI Report Series, which includes the following report types:

- TECHNICAL PUBLICATION. Reports of completed research or a major significant phase of research that present the results of NASA programs and include extensive data or theoretical analysis. Includes compilations of significant scientific and technical data and information deemed to be of continuing reference value. NASA counterpart of peer-reviewed formal professional papers but has less stringent limitations on manuscript length and extent of graphic presentations.

- TECHNICAL MEMORANDUM. Scientific and technical findings that are preliminary or of specialized interest, e.g., quick release reports, working papers, and bibliographies that contain minimal annotation. Does not contain extensive analysis.

- CONTRACTOR REPORT. Scientific and technical findings by NASA-sponsored contractors and grantees.
- CONFERENCE PUBLICATION. Collected papers from scientific and technical conferences, symposia, seminars, or other meetings sponsored or cosponsored by NASA.

- SPECIAL PUBLICATION. Scientific, technical, or historical information from NASA programs, projects, and missions, often concerned with subjects having substantial public interest.

- TECHNICAL TRANSLATION. Englishlanguage translations of foreign scientific and technical material pertinent to NASA's mission.

Specialized services also include creating custom thesauri, building customized databases, organizing and publishing research results.

For more information about the NASA STI program, see the following:

- Access the NASA STI program home page at http://www.sti.nasa.gov

- E-mail your question via the Internet to help@sti.nasa.gov

- Fax your question to the NASA STI Help Desk at 301-621-0134

- Telephone the NASA STI Help Desk at 301-621-0390

- Write to:

NASA STI Help Desk

NASA Center for AeroSpace Information 7115 Standard Drive Hanover, MD 21076-1320 
NASA/TM-2007-214473

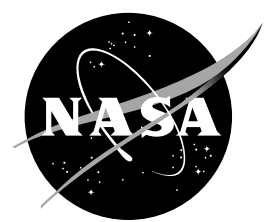

\section{Application of Carbon Based Nano-Materials to Aeronautics and Space Lubrication}

Kenneth W. Street, Jr., and Kazuhisa Miyoshi

Glenn Research Center, Cleveland, Ohio

Randy L. Vander Wal

The Universities Space Research Association, Cleveland, Ohio

National Aeronautics and

Space Administration

Glenn Research Center

Cleveland, Ohio 44135 
This report contains preliminary findings, subject to revision as analysis proceeds.

Trade names and trademarks are used in this report for identification only. Their usage does not constitute an official endorsement, either expressed or implied, by the National Aeronautics and Space Administration.

Level of Review: This material has been technically reviewed by technical management.

Available from

NASA Center for Aerospace Information 7115 Standard Drive

Hanover, MD 21076-1320
National Technical Information Service 5285 Port Royal Road Springfield, VA 22161 


\title{
Application of Carbon Based Nano-Materials to Aeronautics and Space Lubrication
}

\author{
Kenneth W. Street, Jr., and Kazuhisa Miyoshi \\ National Aeronautics and Space Administration \\ Glenn Research Center \\ Cleveland, Ohio 44135 \\ Randy L. Vander Wal \\ The Universities Space Research Association \\ Cleveland, Ohio 44135
}

\begin{abstract}
The tribology program at NASA Glenn Research Center in Cleveland, Ohio, is investigating carbon based nano-particles for their potential in advanced concept lubrication products. Service conditions range from high temperature atmospheric to low temperature vacuum. Some of the lubricants and surface coatings of tribological significance that we have evaluated include neat nano-particles, both grown insitu and as bulk material deposited on the substrate, and nano-particles dispersed in oils which are all highly substrate interactive. We discuss results of testing these systems in a spiral orbit tribometer (SOT) and a unidirectional pin-on-disc (PoD) tribometer.

A Nano-onions/Krytox mixture evaluated as a lubricant for angular contact bearings in air caused a marked lowering of the coefficient of friction (CoF) $(0.04$ to 0.05$)$ for the mixture with an eight-fold improvement in lifetime over that of the Krytox alone. In vacuum, no effect was observed from the nanoonions. Multi-walled nanotubes (MWNT) and graphitized MWNT were tested under sliding friction in both air and vacuum. The MWNT which were grown in-situ oriented normal to the sliding surface exhibited low CoF (0.04) and long wear lives. Bulk MWNT also generate low CoF (0.01 to 0.04, vacuum; and 0.06, air) and long wear life ( $>1$ million orbits, vacuum; and $>3.5$ million, air). Dispersed GMWNT were superior to MWNT and both were superior to aligned MWNT indicating that orientation is not an issue for solid lubrication. Single-walled nanotubes (SWNT) were modified by cutting into shorter segments and by fluorination. All SWNTs exhibited low CoF in air, with good wear lives. The SWNT with slight fluorination yielded an ultra-low CoF of 0.002 although the best wear life was attributed to the nascent SWNT.
\end{abstract}

\section{Introduction}

There are several ways for carbon atoms to bond to form carbon derived materials. Diamond and graphite, the naturally occurring materials, have been mimicked in the laboratory with the development of diamond-like carbon (DLC) and graphite-like carbon (GLC) materials that have been shown to have tribological properties superior to the natural materials in many instances. Carbon also forms smaller, more discrete chemical systems, such as the fullerenes, carbon nanotubes (CNT), and carbon nano-onions (CNO). Many of these latter materials are still in the early stages of tribological investigation. We have found that nano lubricants such as single-walled nanotubes (SWNT), multi-walled nanotubes (MWNT), and graphitized analogues, fluorinated SWNTs, and nano-onions, have superior coefficient of friction $(\mathrm{CoF})$ and endurance lives in ultrahigh vacuum - a space like environment. Potential space and aeronautic applications of nanolubricants include the development of microelectromechanical systems (MEMS), and micromachines. Nanolubricants can be applied to or grown on contacting surfaces in relative motion. Friction contributing to decreased performance, increased energy consumption, wear damage, added maintenance, shortened lives or catastrophic failure constitutes a reliability issue for all contacting interfaces in all mechanical systems. All nanocarbon materials have demonstrated the ability to 
dramatically reduce stiction (or adhesion) and friction between contacting surfaces under dry conditions, a major concern in the development of MEMS and micromachines. Consequently, interest in the research and commercialization of nanotube technology and related materials continues to grow. A recent search by Miyoshi (Miyoshi and Street 2004) shows the number of articles published on this topic to be growing rapidly each year.

Key to the proper functioning of satellites, space vehicles and aircraft are the proper functioning of mechanical components. A large number of specialty oils and solid coatings have been developed to serve the needs of the operating conditions and unique environments of the individual components. Solid lubrication technology has advanced rapidly in the past four decades to where it is extensively used where contamination by liquids is a problem and when liquid lubricants do not meet advanced requirements such as ultra high vacuum (in space), high temperatures, cryogenic temperatures, radiation, clean environments, or corrosive environments, and combinations thereof. Friction and wear are still a primary concern in a large number of current and future applications. Solid lubricants must possess both desirable coefficient of friction (0.001 to 0.3 ) and maintain durability in a variety of environments, such as high vacuum, water, air, both cryogenic and elevated temperature, or dust. The tribological properties of materials and material couples often vary considerably with the environment. Therefore, the successful use of solid lubricants requires an understanding of their properties and knowing how a solid lubricant will perform in a given application. Materials issues such as surface pretreatment, compatibility of counterpart components and lubricants, and debris generation must be taken into account when designing a lubricated device or moving mechanical assembly.

Carbon-derived materials have outstanding lubrication properties and materials such as graphite have been used as lubricants for many decades. Other similar carbon-based materials are the newest durable lubricants. Carbon nano-particles and carbon films such as diamond and graphite-like carbons are presently being investigated for lubrication applications. However, carbon based nano-particles have some unique properties which make them candidates for testing. They appear to be heat resistant, radiation hard, durable and provide low $\mathrm{CoF}(0.01$ to 0.10$)$ with a number of tribocouples. These materials come in many forms. We have tested CNOs (Street, et al., 2004), SWNT, cut SWNT, fluorinated SWNT (Vander Wal, et al., 2005), MWNT, and graphitized MWNT (Miyoshi et al., 2005), under sliding and/or rolling conditions. The nano-tubes have been grown in-situ for testing in a vertically aligned configuration for comparison with randomly scattered neat material coatings. Further, these materials have been tested neat as well as dispersed in oils. The nano-carbon particles are still in the early stages of development, and it will be some time before their practical tribological usage is realized.

\section{Experimental}

\section{Instrumentation}

\section{Spiral Orbit Tribometer}

A Spiral Orbit Tribometer (SOT), (Pepper and Kingsbury 2003 and 2003) simulates an angular contact bearing (fig. 1). A $12.7 \mathrm{~mm}$ (1/2 in.) ball was rolled between a fixed plate and a rotary plate, running at $210 \mathrm{rpm}$. The load, providing a mean Hertz stress of $1.5 \mathrm{GPa}$, was applied through the fixed plate. The combination of the high load, the moderate speed, and of the small amount of lubricant (approximately $50 \mu \mathrm{g}$ ) allowed the system to operate in the boundary lubrication regime. The ball was rolling and pivoting in a spiral and maintained in the orbit by the guide plate. The force the ball exerted on the guide plate was used to determine the friction coefficient. Evaluation of a suspension of nanoonions in Krytox was conducted at room temperature $\left(\sim 23^{\circ} \mathrm{C}\right)$, and under ultrahigh vacuum $\left(\sim 1 \times 10^{-6} \mathrm{~Pa}\right)$ or in air. The relative humidity ranged between 50 and 60 percent for the air tests. As the lubricant was tribologically stressed, it was degraded and eventually consumed. Test conclusion was defined when a friction coefficient of 0.28 was attained. Normalized lubricant lifetime (or inversely, its degradation rate) was then defined as the number of orbits divided by the amount of lubricant in micrograms. All tests were performed at least in duplicate. 


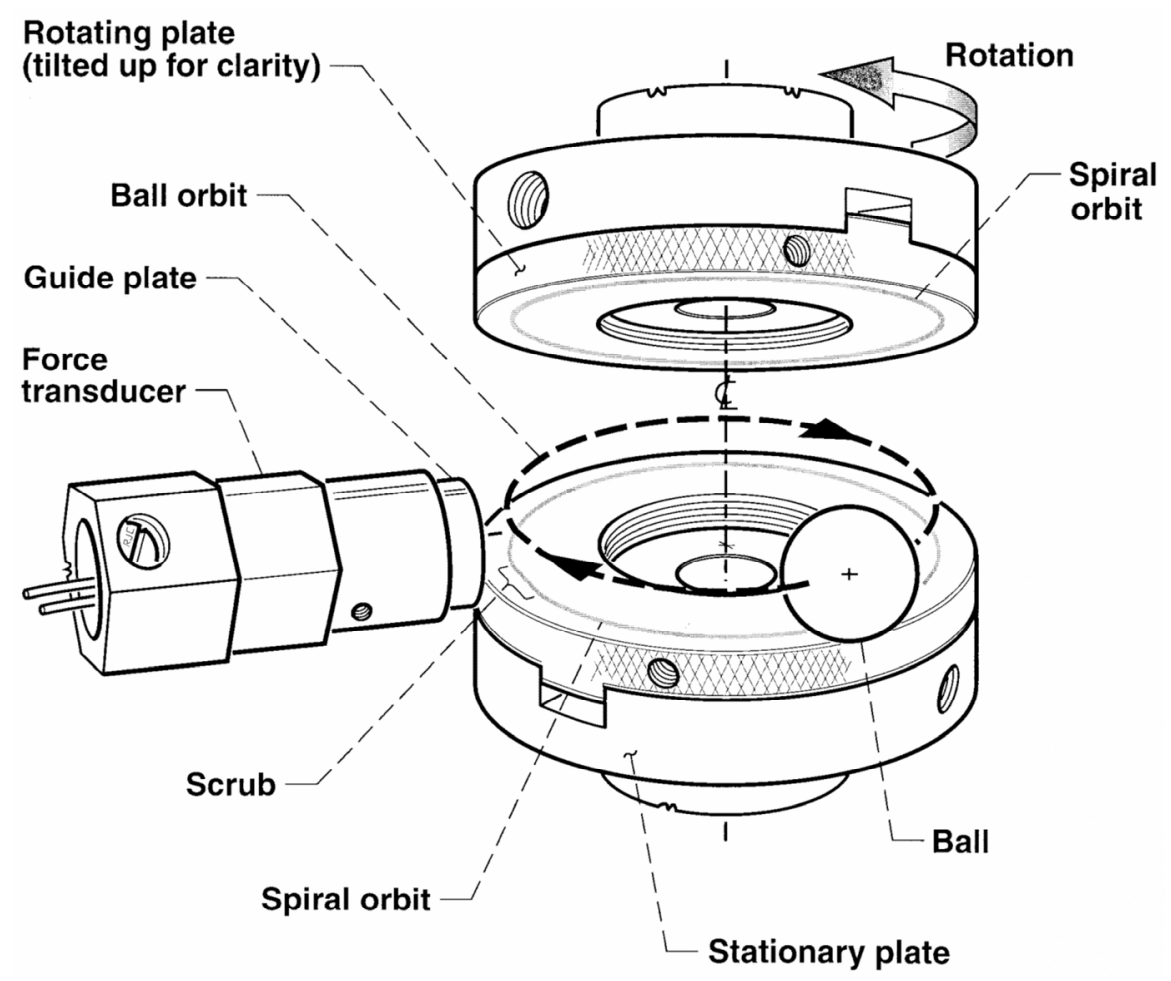

Figure 1.-The Spiral Orbit tribometer.

All specimens were made of American Iron and Steel Institute (AISI) 440C stainless steel. For tribological purposes, ball and plate surfaces were polished to a roughness, $R_{a}$, of $0.05 \mu \mathrm{m}$. The parts were first rubbed with an alumina slurry and rinsed under running deionized water. Then they were ultrasonically cleaned for ten minutes each first in a bath of hexane, followed by deionized water. All drying was done with filtered nitrogen. The procedure was completed by exposing the specimens to ultraviolet/ozone for $15 \mathrm{~min}$.

\section{Pin-on-Disc Tribometer}

The Pin-on-Disc (PoD) tribometer (Miyoshi 1998) used in the investigation was mounted in a vacuum chamber (fig. 2). Unidirectional sliding friction experiments were conducted with the aligned MWNT coatings and the dispersed MWNT (nongraphitized and graphitized) coatings at room temperature in air (relative humidity, $\sim 50$ percent) and in ultrahigh vacuum $\left(\sim 7 \times 10^{-6} \mathrm{~Pa}\right)$. All experiments were conducted with 6-mm-diameter 440C stainless steel balls, and 6-mm-diameter alumina-yttria stabilized zirconia pins in sliding contact with the MWNT films deposited on quartz disk substrates. For SWNT and fluorine modified SWNT, 6-mm-diameter sapphire balls were run against films deposited on quartz. All experiments were conducted with a load of $1.4 \mathrm{~N}$ at $120 \mathrm{rpm}$ using a $6 \mathrm{~mm}$ track diameter. The friction force was continuously monitored during the sliding friction experiments. The sliding wear life, endurance life, for the coatings was determined to be the number of passes at which the CoF rose to 0.15 in a given environment.

\section{Sample Preparation}

\section{Spiral Orbit Tribometry Samples}

Samples of carbon precursor were heat-treated in a resistance heated furnace using a graphite crucible under a He atmosphere. The nano-onions were obtained by inductive heating at $3000^{\circ} \mathrm{C}$ for $1 \mathrm{hr}$. duration and were used without further treatment (e.g. purification). The nano-onions appeared to be stable in air. 


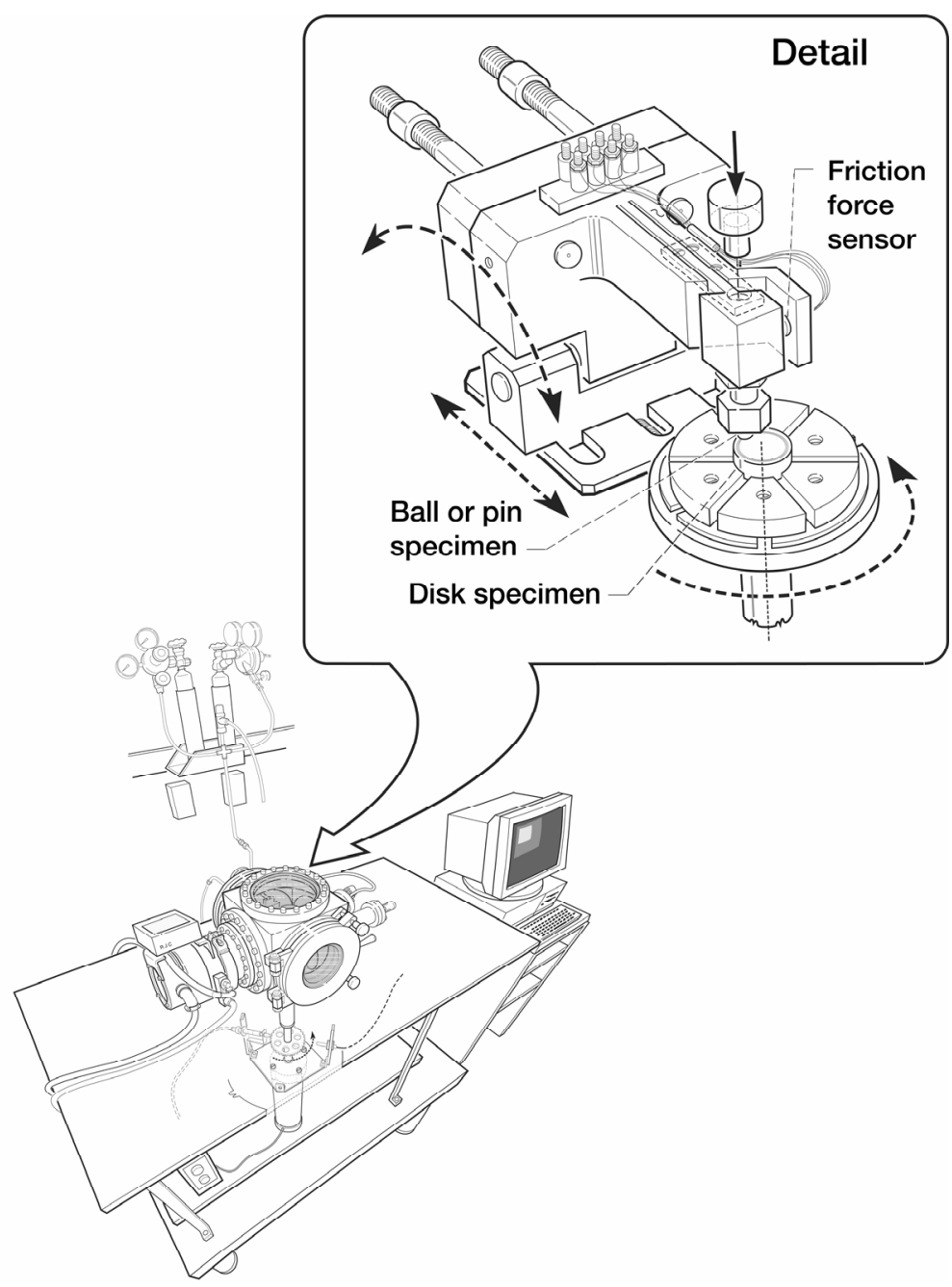

Figure 2.-The Pin-on-disc tribometer.

These materials were characterized by transmission electron microscopy, TEM, (Vander Wal, et al., 2004), thermo gravimetric analysis (TGA), and infrared and Raman spectroscopic analysis (Street, et al., 2004).

A solution of CNO in Krytox $143 \mathrm{AB}$ oil, already used in space applications, was prepared. It consisted of $10.3 \mathrm{mg}$ of oil and $5.16 \mathrm{ml}$ of solvent. Therefore, when $25 \mu \mathrm{l}$ of the dilute solution was applied with a micro syringe on the ball, $50 \mu \mathrm{g}$ of oil was left after evaporation of the solvent. The CNO particles were added in such a quantity that roughly a 20 percent (by weight) suspension was created. A quick visual observation showed that the particles were agglomerated, so as to have a proper suspension, the dilute solution of oil, particles and solvent was agitated in an ultrasonic bath before use resulting in a completely black solution with dispersed particles.

\section{Pin-on-Disk Tribometry Samples}

Aligned MWNTs. - The aligned MWNTs were synthesized within a high-temperature tube furnace around $800{ }^{\circ} \mathrm{C}$ on catalyst-coated quartz substrates. Physical vapor deposition was used to coat all quartz substrates with a 5-nm thick iron bondcoat, which formed iron islands resembling droplets and served as catalyst particles on the quartz. The procedure for creating the aligned MWNTs directly upon the catalystcoated quartz disks involved (1) initial heat up, (2) catalyst reduction, (3) further temperature elevation, and (4) synthesis using xylene as the carbon source, (5) followed by cooling under an inert environment. 
Specifically, iron coated specimens $\left(5 \mathrm{~nm}\right.$ thickness) are held at $700{ }^{\circ} \mathrm{C}$ for $1 \mathrm{hr}$ within a flow of $\mathrm{Ar}: \mathrm{H}_{2}$ (4:1), followed by ramping to $850{ }^{\circ} \mathrm{C}$ under argon. Then to synthesize the MWNTs, the xylene is introduced for $25 \mathrm{~min}$. through a pre-evaporator $\left(0.4 \mathrm{ml} \cdot \mathrm{min}^{-1}\right.$ feedrate $)$ using a metering pump with a carrier flow of Ar: $\mathrm{H}_{2}$ of 5:1.

Dispersed MWNTs.-In the CVD process, $6.5 \mathrm{~mol} \%$ of ferrocene is dissolved in xylene to obtain a feed solution with approximately 0.75 percent of iron to carbon which is fed continuously into a twostage tubular reactor using a syringe pump. Ferrocene (sublimation temperature, $\sim 140{ }^{\circ} \mathrm{C}$ ) has been shown to be a good precursor for producing iron catalyst particles that can seed nanotube growth, and xylene was selected as the hydrocarbon source since it boils $\left(\sim 140^{\circ} \mathrm{C}\right)$ below the decomposition temperature of ferrocene $\left(\sim 190^{\circ} \mathrm{C}\right)$. The liquid feed is passed through a capillary tube and preheated to $\sim 175^{\circ} \mathrm{C}$ prior to its entry into the furnace. At this temperature, the liquid exiting the capillary is immediately volatilized and swept into the reaction zone of the furnace by a flow of argon with 10 percent hydrogen. Various parameters, such as the furnace temperature $\left(650\right.$ to $\left.1050{ }^{\circ} \mathrm{C}\right)$, ferrocene-xylene ratio and feed rate, total reaction time, and sweep gas flow rate were adjusted to determine the optimal growth conditions for high-purity MWNTs. After the reaction, the preheater and the furnace were allowed to cool to room temperature in flowing argon. Carbon deposits were formed on the walls of the quartz furnace tube and on plain quartz substrates that were placed within the furnace to act as additional sites for nanotube growth. The nanotube material was scraped clean from the walls of the reactor tube and weighed. The reactor was operated modestly above atmospheric pressure to prevent any influx of oxygen.

Graphitized MWNTs were obtained by heating collected MWNTs within a graphite tube furnace under inert atmosphere. Temperatures exceeded $1550{ }^{\circ} \mathrm{C}$ for several hours, permitting melting, draining, and vaporization of residual Fe catalyst. A potential added benefit of the heating is that some additional graphitization occurs within the nanotubes. Defects may be annealed and lattice planes oriented more parallel to each other, as in graphite. Other details are proprietary.

Since the MWNTs were agglomerated, in order to have a proper suspension, a dilute solution of MWNT particles and solvent was placed in an ultrasonic bath prior to deposition on a quartz disk surface. The dispersed MWNT coating films were prepared by deposition of the dilute MWNT suspension on quartz disks followed by evaporation of solvent under dry nitrogen flow. Coating films with four different relative thicknesses $\left(0.63,1.26,1.89\right.$, and $\left.2.52 \mu \mathrm{g} \cdot \mathrm{mm}^{-2}\right)$ were fabricated. The most unambiguous measure of thickness is weight per unit area which we use to define the coating load. Bonding between a coating and the substrate is due to van der Waals' forces. The nanotubes are mechanically tangled with each other. The standard thickness of $2.52 \mu \mathrm{g} \cdot \mathrm{mm}^{-2}$ was used in most experiments unless otherwise specified.

Dispersed SWNTs.-All SWNTs were prepared by the High Pressure CO Conversion (HiPCO) process, and were purified prior to use by wet air oxidation and subsequent hydrochloric acid treatment followed by washing and vacuum drying to remove all nontubular forms of carbon and iron catalyst according to a documented detailed procedure (Chiang, et al., 2001). The iron content in the purified SWNTs was found to be $<1 \mathrm{wt} \% \%$ according to thermo-gravimetric analysis. The fluoronanotubes of the $\mathrm{C}_{2} \mathrm{~F}$ and $\mathrm{C}_{5} \mathrm{~F}$ stoichiometry were prepared by direct fluorination of purified SWNTs under controlled, well-established conditions (Khabashesku, et al., 2002 and Gu, et al., 2005). Hydrazine treatment of the $\mathrm{C}_{2} \mathrm{~F}$ sample was used to reduce the fluoronanotubes to approximately a $\mathrm{C}_{20} \mathrm{~F}$ composition (Khabashesku and Margrave, 2004 and Khabashesku, et al., 2002). Cut-SWNTs of 100 to $300 \mathrm{~nm}$ lengths were prepared by treatment of SWNTs in $2 \mathrm{M} \mathrm{HNO}_{3}$ by 30 min sonication (Khabashesku and Margrave, 2004). Pyrolysis of $\mathrm{C}_{5} \mathrm{~F}$ fluoronanotubes in argon produced shorter nanotubes, F-cut-SWNTs, of predominantly 20 to $80 \mathrm{~nm}$ length distribution (Gu, et al., 2002).

The films were prepared by deposition of nanotube sample suspensions either in toluene (SWNTs, cut-SWNTs, and $\left.\mathrm{C}_{20} \mathrm{~F}\right)$ or isopropanol $\left(\mathrm{C}_{2} \mathrm{~F}, \mathrm{C}_{5} \mathrm{~F}\right.$, and F-cut-SWNTs) on the quartz disk followed by evaporation of solvent under dry nitrogen flow. Films of four different relative thicknesses $(0.63,1.26$, 1.89 , and $\left.2.52 \mu \mathrm{g} / \mathrm{mm}^{2}\right)$ were fabricated and tested. All tests were run in air environment $(\sim 0 \%$ relative humidity) at room temperature $\left(\sim 23^{\circ} \mathrm{C}\right)$. 


\section{Analytic Techniques and Post Mortem Analysis}

For characterization of the $\mathrm{CNO}$ and SOT postwear analyses, all infrared spectra were collected with an Fourier Transform Infra Red (FTIR) spectrometer with the sample mounted in a $7.6 \mathrm{~cm}$. diameter gold coated integrating sphere (Street, et al. 2007). A Raman microscope that uses a $25 \mathrm{~mW}$ Ar Ion laser operating at $514.5 \mathrm{~nm}$ was employed to collect Raman spectra. The microscope objective was typically $20 \mathrm{X}$ with occasional spectra taken at $10 \mathrm{X}$ or $50 \mathrm{X}$ having spot diameters of 14,28 , and $5 \mu \mathrm{m}$ respectively.

In postwear analyses of MWNT samples, high-resolution transmission electron microscopy (HRTEM) and scanning electron microscopy (SEM) were used to determine nanostructure, microstructure, morphology, and defects of materials; electron energy loss spectroscopy (EELS) and energy dispersive x-ray analysis (EDX) were used for elemental analyses and stoichiometry of materials; and vertical scanning interferometry was used to determine surface topography and roughness, film or layer thickness, and wear volume. For the postwear analysis of SWNT samples, transmission electron microscopy (TEM) was used to determine nanostructure, microstructure, morphology, and defects of materials.

\section{Results and Discussion}

\section{Nano-onion Investigations}

\section{Background and Objectives}

Soot, carbon material, represents one of the very first nanostructured materials, although it has rarely been considered as such. Careful examination of the internal structure of these carbon materials reveals that the nanostructure is highly variable and depends upon the starting material and processing conditions, which is also true of carbon black (Donnet, et al., 1993). The significance with respect to oxidation of the internal structure of carbon is its effect upon reactivity. In general, more graphitic carbons are less reactive towards oxidation (Thomas, 1965). Graphitic carbon is characterized by layer planes with large in-plane dimensions (Marsh, 1989). The connection between layer plane dimensions and oxidation is due to the anisotropic reactivity of the graphitic segments comprising the carbon. Carbon atoms within basal plane sites, surrounded by other carbon atoms, exhibit a far lower oxidative reactivity than those located at the periphery of such segments, so-called edge sites (Rosner, and Allendorf, 1968).

Changes in the carbon nanostructure, resulting in increased graphitic layer plane length, are correlated with reactivity loss (Davis, et al., 1995). Layer plane segments can grow by bonding to adjacent graphene segments and by addition of amorphous carbon material within the soot particle from which they are produced (Vander Wal and Choi, 1999). Whether thermally or oxidatively induced, an increase in the dimensions of graphene segments corresponds to graphitization and a parallel decrease in reactivity. Upon heating spherically shaped carbon black of nanometer scale dimensions in the absence of oxidant, graphene sheets form and the initial soot particle templates the growth of a graphitic particle into what is best described as a "sphere" with many flat sides, i.e., polygonal in nature and having a hollow interior. Due to the absence of edge sites, these polygonal graphitic particles, or CNOs, are relatively stable toward oxidation (Vander Wal, et al., 2004). High resolution TEM images of the nano-onions (fig. 3(a)), and carbon precursor (fig. 3(b)) indicate the significant change in structure of the material upon graphitization. In these images, the dark lines indicate the graphene sheets of carbon atoms and the white lines are the spacing between sheets. The annealing process allows ordering of the sheets and length extension of the flat crystalline regions resulting in considerable basal plane sites of low reactivity toward oxidation. The polygonal connection of basal planes eliminates edge sites to further reduce reactivity. 

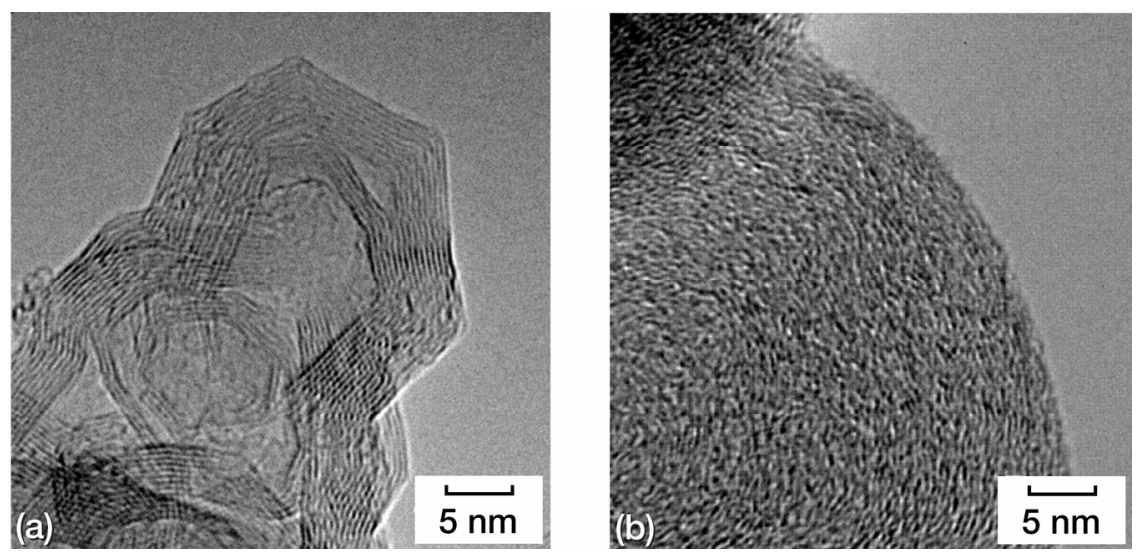

Figure 3.-High-resolution transmission electron micrograph of

(a) nano-onions and (b) carbon precursor.
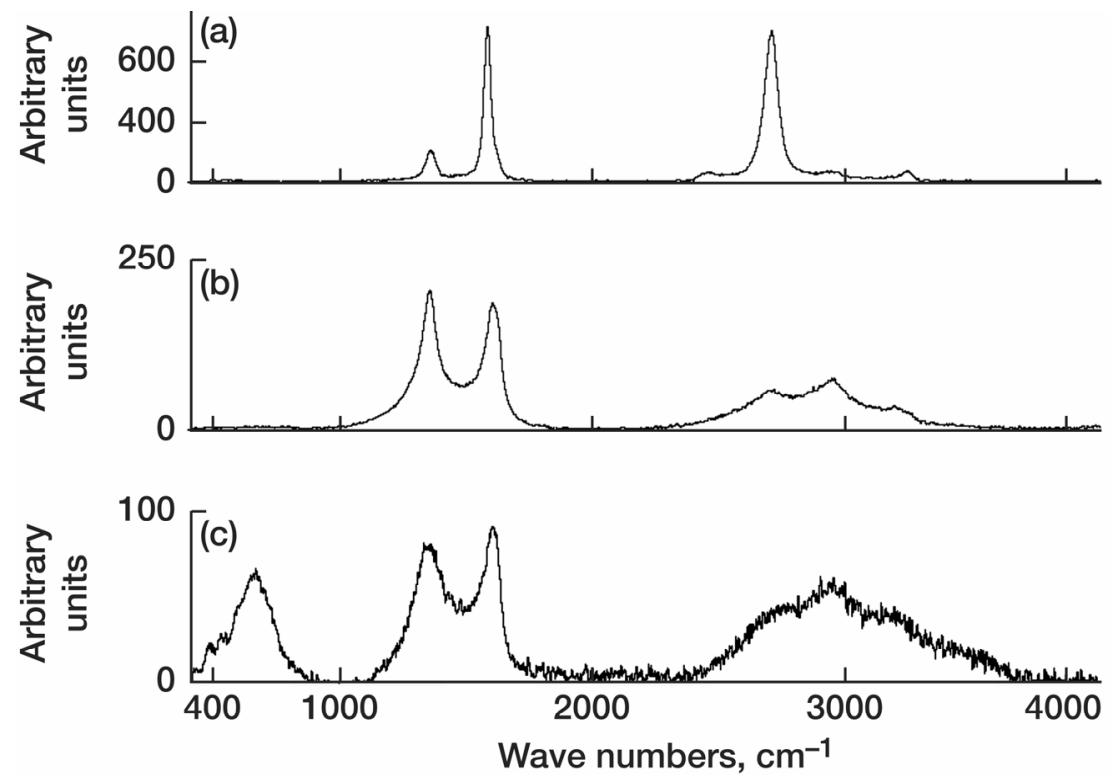

Figure 4.--Raman spectra of carbon materials. (a) Nascent nano-onions.

(b) Postmortem spectrum from 440C stainless steel ball run in vacuum with Krytox 143AB/nano-onion mixture. (c) Postmortem spectrum from 440C stainless steel ball run in air with Krytox 143AB/nano-onion mixture.

While we have not measured the size distribution of the graphitized materials, the primary particle size, initially around $30 \mathrm{~nm}$ in diameter, is conserved in the graphitization process.

Raman spectroscopy has been frequently used in the characterization of graphite and graphitic materials. The spectra shown in figure 4 have been normalized to account for differing acquisition conditions. Two spectral peaks characterize the first order Raman spectra of carbon materials (fig. 4(a)); a peak near $1580 \mathrm{~cm}^{-1}$, the "G-band," and a peak near $1360 \mathrm{~cm}^{-1}$, the "D-band" (Tuinstra and Koenig, 1970). The former corresponds to an in-plane stretching motion of the graphitic layer planes. The latter arises from a breakdown of the Raman selection rules attributed to the finite-sized regions of graphitic structure, hence its nomenclature as the "disorder activated" transition. The narrowing of the D and G peaks indicates increasing homogeneity of the sample as disordered carbon is reorganized into graphitic sheets. The spectra obtained from the nano-onions contained sharp D and G peaks with the G peak much more intense indicating a highly ordered material considerably different from the starting carbon precursor. In addition, the second order region between 2520 and $3300 \mathrm{~cm}^{-1}$ contains a sharp, intense 


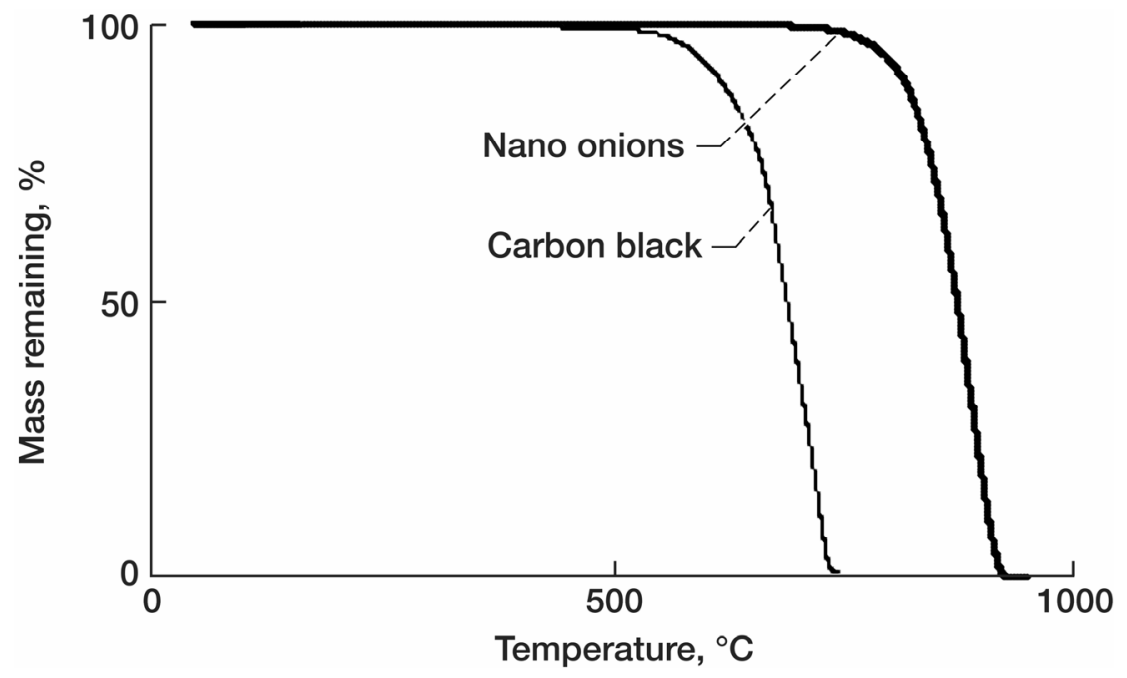

Figure 5.-Comparative thermo-gravimetric analysis of carbon precursor and nascent nano-onions.

band at $2696 \mathrm{~cm}^{-1}$ for highly ordered graphitic materials, like the CNO. This band is virtually absent in the degradation products and the starting carbon precursor (Hiura, et al., 1993).

Graphite is used as a solid lubricant due to its stability at moderately high temperatures. However, the temperature at which the graphite rapidly oxidizes is strongly influenced by surface area (Braithwaite, 1964). With the size of particles typically employed in lubrication, a great amount of thermal stability is lost due to size reduction either during grinding for application or during lubrication of contacting parts. The TGA analyses of the nano-onions and carbon precursor in air both indicate high purity materials having normal TGA profiles (fig. 5). The points at which 5 percent of the materials are oxidized indicate the approximate temperature where rapid oxidation of these materials proceeds. For the carbon precursor, this temperature is $588^{\circ} \mathrm{C}$ and for the $\mathrm{CNO} 792{ }^{\circ} \mathrm{C}$, indicating the improved oxidation resistance of the graphitic nanostructured material. For this reason, we have undertaken a study of the lubricating ability of nano-structured graphitic particles such as CNO and CNT.

\section{CNO Tribology}

The lubrication role of solid particles introduced in a fluid lubricant, i.e., in grease, depends on the size of the particles, on their amount, and on the geometry of the contact. The introduction of small particles is beneficial in boundary lubrication, but particles present in the lubricant have to be of small size so as to allow a good fluid circulation within the contact and to not "jam" it. The amount of particles is generally low, a few percent in volume, and up to 10 percent for graphite (Wan and Spikes, 1988). Under severe conditions, these particles can produce a layer which helps to protect the surfaces (Wan and Spikes, 1988, and Wunsch, 1991). Hence, the evaluation of the ability of graphitic CNOs to improve the lubricating lifetime of a space oil, Krytox $143 \mathrm{AB}$, in conditions simulating bearing operation was undertaken.

After SOT testing at room temperature the average normalized lifetime, the number of orbits performed before failure per microgram of lubricant employed, was calculated. Examples of friction traces and the lifetime obtained are given in figure 6 and table 1, respectively. The use of CNOs did not improve the lifetime, nor did it change the friction coefficient of the Krytox 143AB, a perfluorinated polyether (PFPE), oil run in vacuum. Results of testing in air are reported in figure 6 and table 1. A very low friction coefficient ( 0.04 to 0.05$)$ was observed with a long lifetime in air. Furthermore, the failure was more "progressive" compared to the one observed in vacuum. In air however, a significant improvement in lifetime occurs (fig. 6, lower scale) attributed to the CNOs, which arises from their ability 


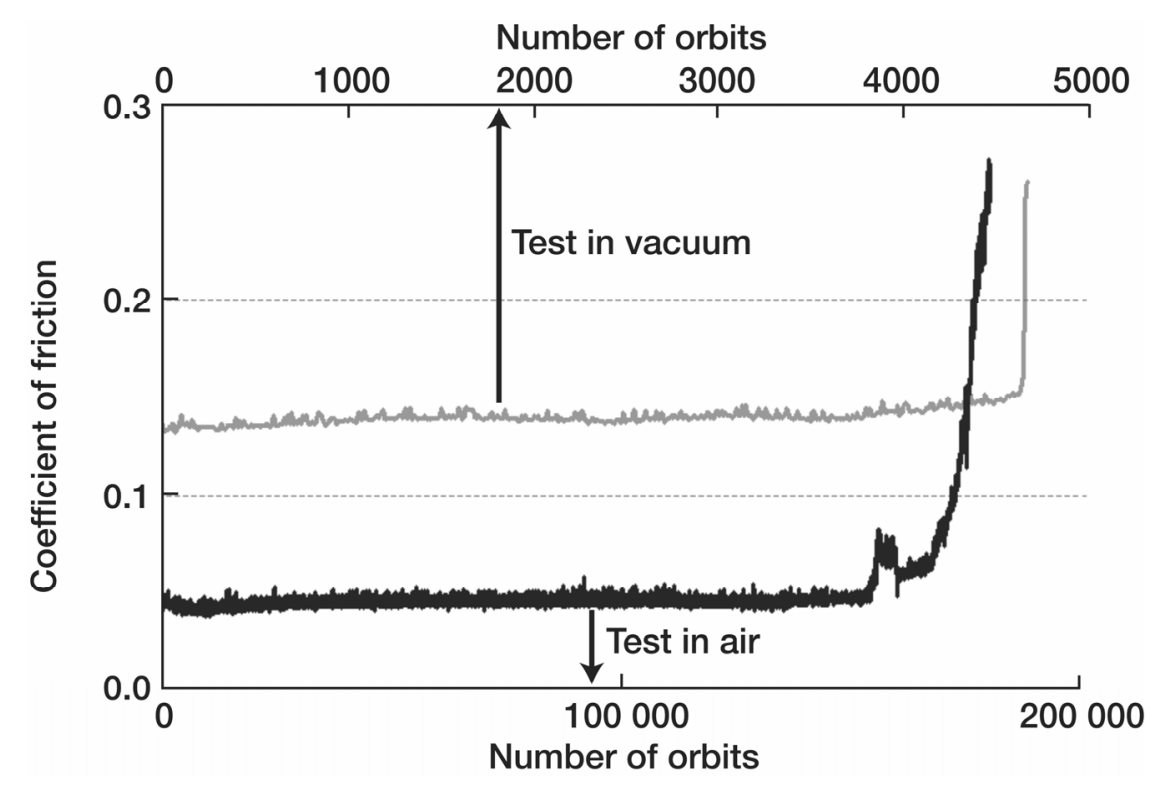

Figure 6.-Coefficient of friction traces for tests run in vacuum (upper scale) and in air (lower scale) with Krytox 143AB with nano-onions.

TABLE 1.-COEFFICIENT OF FRICTION AND NORMALIZED LIFETIMES FOR KRYTOX 143AB AND KRYTOX 143AB WITH NANO-ONIONS IN DIFFERENT ENVIRONMENTS

\begin{tabular}{|l|l|c|c|}
\hline \multicolumn{1}{|c|}{ Sample } & \multicolumn{1}{|c|}{ Environment } & Coefficient of friction & Lifetime \\
\hline Krytox 143AB & Air & 0.13 & 476 \\
Krytox 143AB & Vacuum & 0.13 & 43 \\
Krytox 143AB/CNO & Air & 0.05 & 3830 \\
Krytox 143AB/CNO & Vacuum & 0.13 & 55 \\
\hline
\end{tabular}

to serve as a back-up lubricant. The nano-onions from the suspension are forming a lubricant layer on the surfaces of the ball and disk, similar to Teflon thickener in commercial PFPE based greases. The nanoonions can replace the degraded oil as a lubricant, forming a graphitic material. Postmortem analysis indicates that the CNOs are sacrificed to form an amorphous graphitic layer. This behavior is typical of graphite which lubricates better in humid air. Similar superior tribological properties of CNO films is reported for PoD experiments (Hirata, et al., 2004). In those experiments, the CNOs formed by heat treatment of diamond were more spherical with shorter graphene lamella, and produced $\mathrm{CoF}$ of $\sim 0.05$ for the tribocouple of steel on a silicon wafer.

Raman analysis on the balls run in vacuum (fig. 4(b)) indicated the presence of a large quantity of graphitic material having well defined $\mathrm{D}$ and $\mathrm{G}$ peaks as well as multiple small peaks in the second order peak region. These spectra are not similar to the applied CNOs but are similar to conventionally degraded carbon based lubricants. It is thus concluded from the Raman analysis that the nano-onions degrade during tribological contact and that they are completely consumed at failure. It should be noted that the CNOs degrade to produce spectra similar to degraded PFPE lubricants so it is not possible to distinguish the source of the degraded material. The ball run in air (fig. 4(c)) had similar spectral features but at much lower concentrations.

Infrared analysis was also performed postmortem on the balls (fig. (7)). Balls run in either air or vacuum showed peaks in the 2960 to $2850 \mathrm{~cm}^{-1}$ range and a broad band in the $3360 \mathrm{~cm}^{-1}$ range. These bands correspond to hydrocarbon and oxygenated materials (possibly water) respectively. No further evidence of oxygenated functional groups was found in either spectrum. The ball run in vacuum (fig. 7(b)) revealed traces of the original Krytox $143 \mathrm{AB}$ having bands in the 1346 to $970 \mathrm{~cm}^{-1}$ region of 

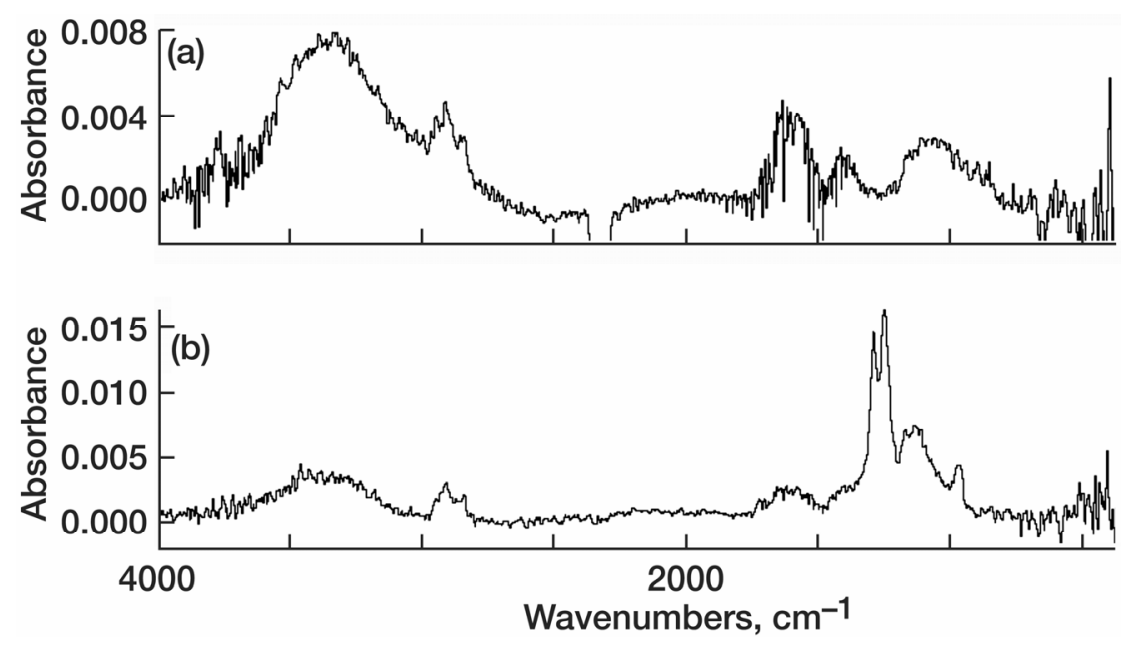

Figure 7.--Infrared spectra of the Krytox $143 \mathrm{AB}$ with nano-onions after the tests run in (a) air and (b) vacuum.

the spectrum. This result is unexpected since all the lubricant is typically consumed during a SOT experiment.

\section{Conclusions on CNO Tribology}

1. The CNOs provide lubrication similar to graphite when tribologically tested in ambient air.

2. The CNOs degrade to a final material characteristic of the degradation of other carbon-based lubricants.

3. The CNOs are stable in air to over $750{ }^{\circ} \mathrm{C}$ with stability attributed to the lack of edge sites vulnerable to oxidation.

4. These nano-structured materials are of the correct particle size range to allow adequate circulation of lubricants but still provide back-up lubrication under extreme conditions. These results suggest that the CNOs could also be used as a solid additive to grease replacing Teflon or $\mathrm{MoS}_{2}$ in several commercially available lubricants for use in ambient air.

\section{Multi-walled Nanotube Investigations}

\section{Background and Objectives}

In 1991, CNTs - long, thin cylinders of carbon —-were discovered by Iijima (Iijima, 1991). A CNT is often described as a honeycomb lattice rolled into a cylinder. CNTs consist of graphene cylinders closed at either end with caps containing pentagonal rings. They are actually part of the fullerene family: essentially buckyballs expanded from the center into cylinders. CNTs may be either single- or multiwalled. Both types possess remarkable physical, electronic, and thermal properties. For example, the Young's modulus of single-walled CNTs lies close to $1 \mathrm{TPa}$, and the maximum tensile strength is close to $30 \mathrm{GPa}$ (Yu, et al., 2000), with values for multi-walled CNTs being somewhat less. The precise values depend upon the CNT diameter, length, chirality, and number of walls and defects. Their intriguing structures have sparked much excitement in recent years, and a large amount of research has been dedicated to understanding them.

The CNTs are still in the early stages of development in the field of tribology, and it will be some time before practical tribological usage is realized. Tribology applications may emerge that can take full advantage of intrinsic structures and properties of carbon-based nanomaterials and films in such areas as solid films for dry lubrication, additives for liquid lubricants and greases, and composites for wear parts (Street, et al., 2004, Miyoshi and Street, 2004, Hirata, and Yoshioka, 2004, Fernandez-Palacio, et al., 
2004, and JolyPottuz, et al., 2004). These films and materials may offer attractive new solutions to important lubrication problems as well as exciting challenges to the tribologist or product designer who seeks to exploit the performance and cost-effective potential of these materials.

The primary objective of this section is to report our investigations on the steady-state CoF and endurance or wear life of MWNTs. Aligned MWNTs, dispersed nongraphitized MWNTs, and dispersed graphitized MWNTs were synthesized and coated on quartz disk substrates. To evaluate the friction behavior, unidirectional sliding friction experiments were conducted with $440 \mathrm{C}$ stainless steel balls and hemispherical alumina-yttria stabilized zirconia (Al-YSZ) pins in sliding contact with the MWNTs at room temperature in air and in ultrahigh vacuum. The main criterion for evaluating the solid-lubrication performance of materials was the CoF; it was determined that an effective solid lubricating material must generally have a $\mathrm{CoF}<0.15$ in any given environment. Postwear analyses of wear surfaces, transfer films, wear debris, and microstructures were conducted. Finally, the lubrication mechanism of the nanostructured MWNTs is discussed.

\subsubsection{Nano- and Microstructure of MWNT Solid Films}

In figure 8, a series of SEM images show MWNTs aligned perpendicularly to the substrate, densely grown as MWNT mats, "nanograss," on quartz. The high density of growth is the causative factor for the alignment. In contrast, figure 9 presents SEM images of dispersed nongraphitized and graphitized MWNTs showing a tangle of long, thin cylinders (tubular, nanofiber-like particles). The directions of the
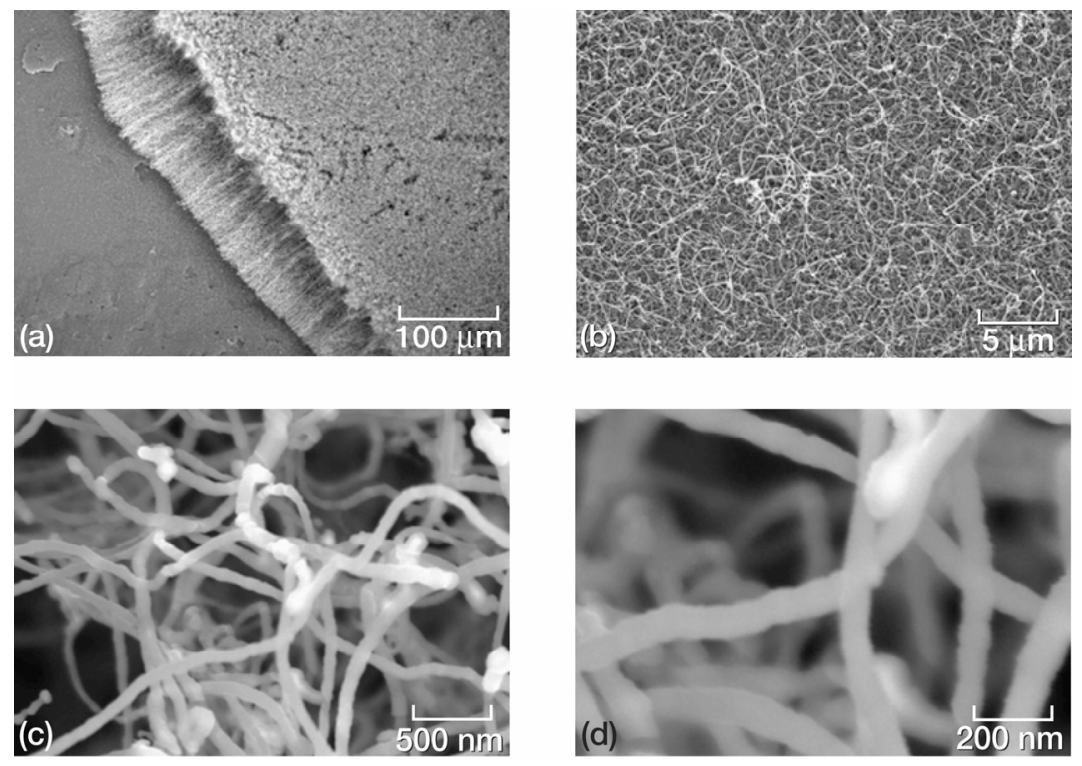

Figure 8.-Scanning electron micrographs of aligned multi-walled carbon nanotubes (MWNTs) grown on iron-coated quartz.
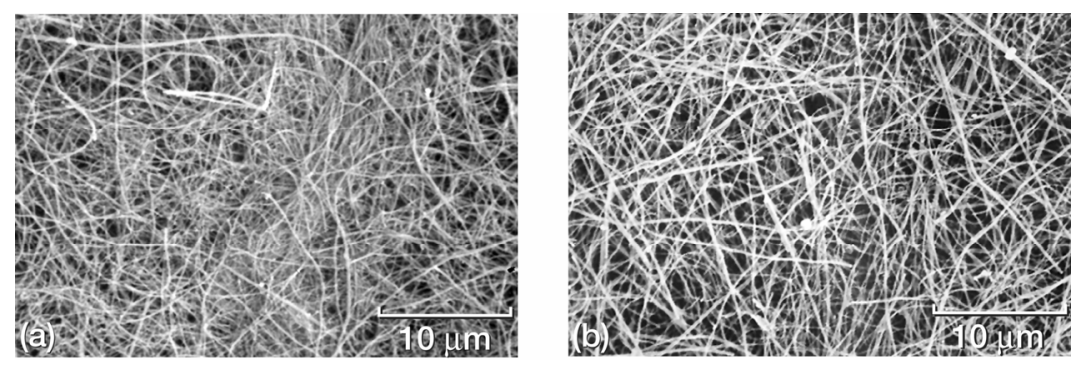

Figure 9.-Scanning electron micrographs of dispersed multi-walled carbon nanotubes (MWNTs) deposited on quartz. (a) Nongraphitized.

(b) Graphitized. 

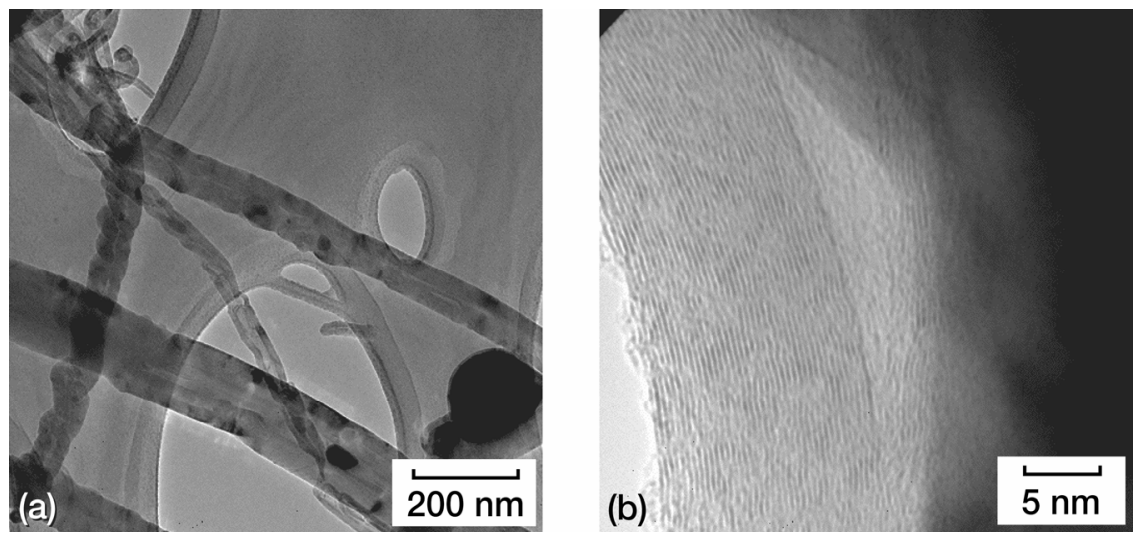

Figure 10.-High-resolution transmission electron micrograph of dispersed nongraphitized MWNTs.
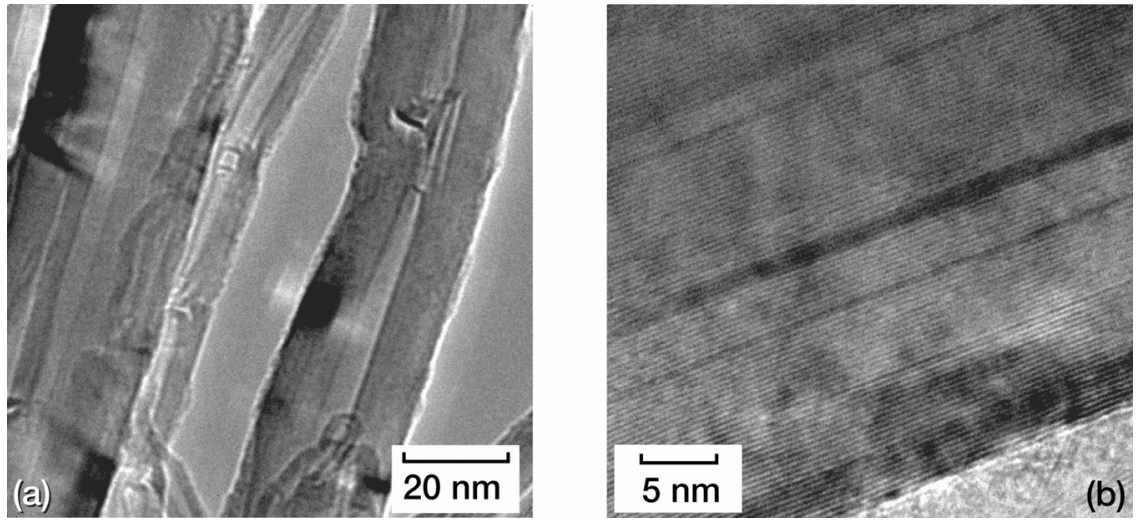

Figure 11.-High-resolution transmission electron micrograph of dispersed graphitized MWNTs.

cylinders are randomly oriented and are generally "parallel" to the surface of the substrate. Figures 10 and 11 show HRTEM images of the dispersed as-synthesized nongraphitized and graphitized MWNTs, respectively. These images are included here as a reference for post-wear analysis.

As seen in figure 10, the nongraphitized MWNTs possess different diameters yet invariably have the traditional inner channel, a characteristic of graphitic MWNTs. Some segmentation appears and is related to the uniformity of their growth process. The HRTEM image shows a wall structure with some breaks and discontinuities among the carbon lamellae. By comparison, in figure 11 the HRTEM images of the graphitized MWNTs show the graphitic nature of a section of the sidewall. Segmentation is still observed in the MWNTs; however, some breaks and discontinuities among the carbon lamellae noticeable in the nongraphitized MWNTs are absent from the graphitized MWNTs. These graphitized MWNTs have been dispersed upon quartz, per the above procedure and their friction properties will be described later.

\section{Tribology of MWNT}

Aligned MWNTs. - Figure 12 presents friction traces obtained in humid air for an aligned MWNTcoated disk, an iron-coated quartz disk, and a bare quartz disk in sliding contact with a 440C stainless steel ball as a function of the number of passes. All the friction traces obtained with the three different disks fluctuated. The steady-state CoF for the aligned MWNT coating in contact with 440C stainless steel was between 0.025 and 0.060 which meet the friction criterion in humid air. The average CoF was 0.04 , 


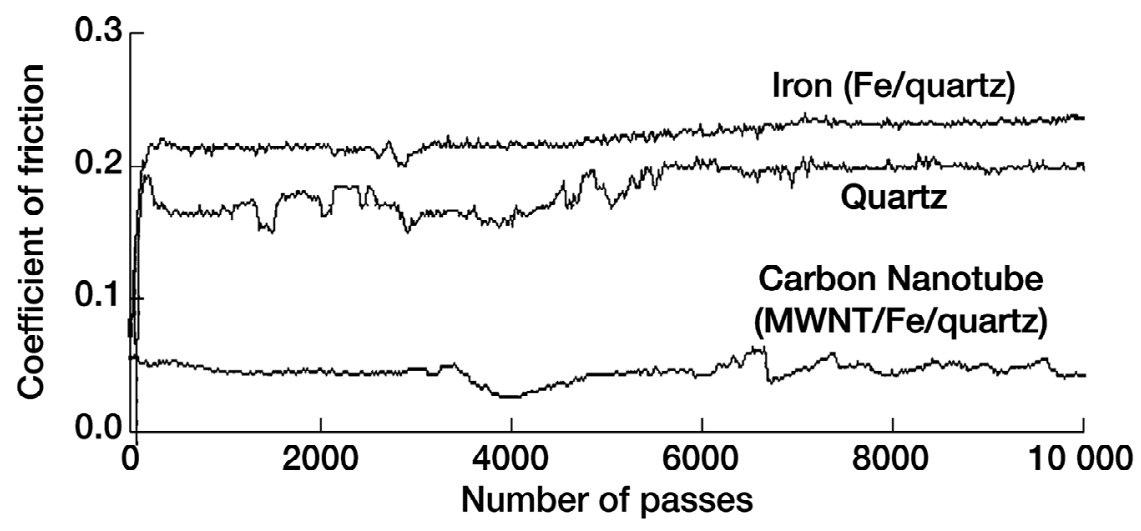

Figure 12.-Coefficient of friction for aligned MWNT coating (MWNT/Fe/quartz), iron-coated quartz (Fe/quartz), and bare quartz in sliding contact with $440 \mathrm{C}$ stainless steel balls in air as a function of number of passes.
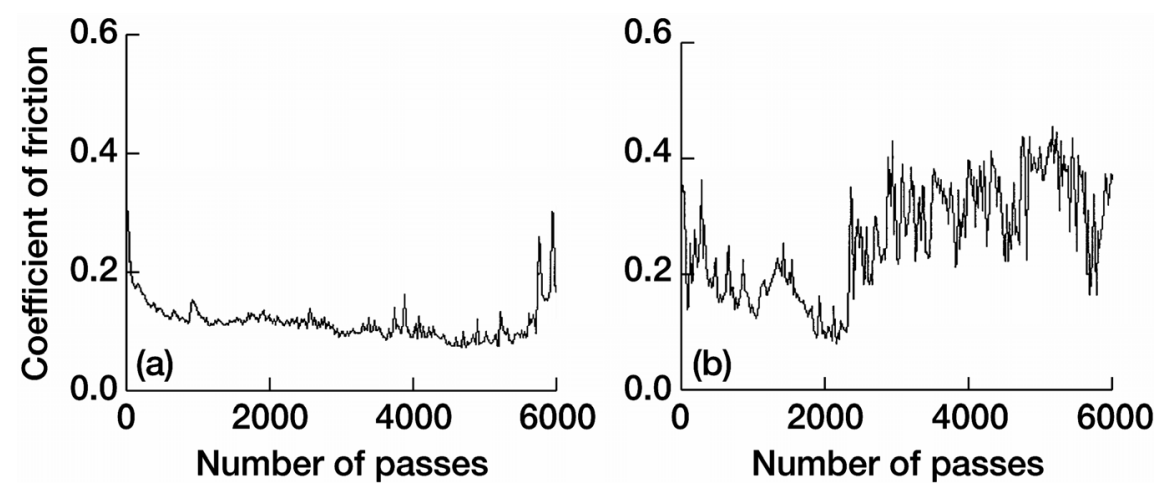

Figure 13.-Coefficient of friction for (a) aligned MWNT coating (MWNT/Fe/quartz) and (b) bare quartz in sliding contact with AI-YSZ hemispherical pins in ultrahigh vacuum as function of number of passes.

which is one-fourth to one-fifth of the averages for the bare quartz and the iron-coated quartz reference blanks. The wear life of this typical aligned MWNT coating was 172,500 passes.

In ultrahigh vacuum, the $\mathrm{CoF}$ for the aligned MWNT coating in contact with $440 \mathrm{C}$ stainless steel fluctuated between 0.19 and 0.48 , while that for the bare quartz fluctuated between 0.40 and 0.59 and that for the iron-coated quartz fluctuated between 0.19 and 0.54 . The material couple of the aligned MWNTs and $440 \mathrm{C}$ stainless steel did not meet the friction criterion in ultrahigh vacuum.

Therefore, a different counterpart material was chosen to improve the friction behavior of the aligned MWNT coating in ultrahigh vacuum. Two-phase Al-YSZ ceramic (Miyoshi, et al., 2004) was selected: it is harder, but lighter, than the stainless steel and is more inert chemically. The PoD results are presented in figure 13. In ultrahigh vacuum, the steady-state CoF for the aligned MWNT coating in contact with AlYSZ was between 0.073 and 0.11 , while that for the bare quartz fluctuated between 0.17 and 0.46 and that for the iron-coated quartz fluctuated between 0.18 and 0.53 . The average CoF for the aligned MWNT coating in contact with Al-YSZ was 0.09 , nearly one-third to one-fourth of those for the bare quartz and the iron-coated quartz. The material couple of the aligned MWNTs and Al-YSZ met the friction criterion in ultrahigh vacuum, although the wear life was only about 5,700 passes.

Dispersed MWNTs. - Figure 14 presents friction traces for the dispersed, nongraphitized MWNTs and the dispersed, graphitized MWNTs in sliding contact with Al-YSZ in humid air and in ultrahigh vacuum, respectively, as a function of the number of passes. Both friction traces fluctuated. In air, the average $\mathrm{CoF}$ for the dispersed, nongraphitized MWNT coating with a coating thickness of $2.52 \mu \mathrm{g} \cdot \mathrm{mm}^{-2}$ was 0.06 . The wear life of this particular MWNT coating was greater than 3.5 million passes. In ultrahigh 

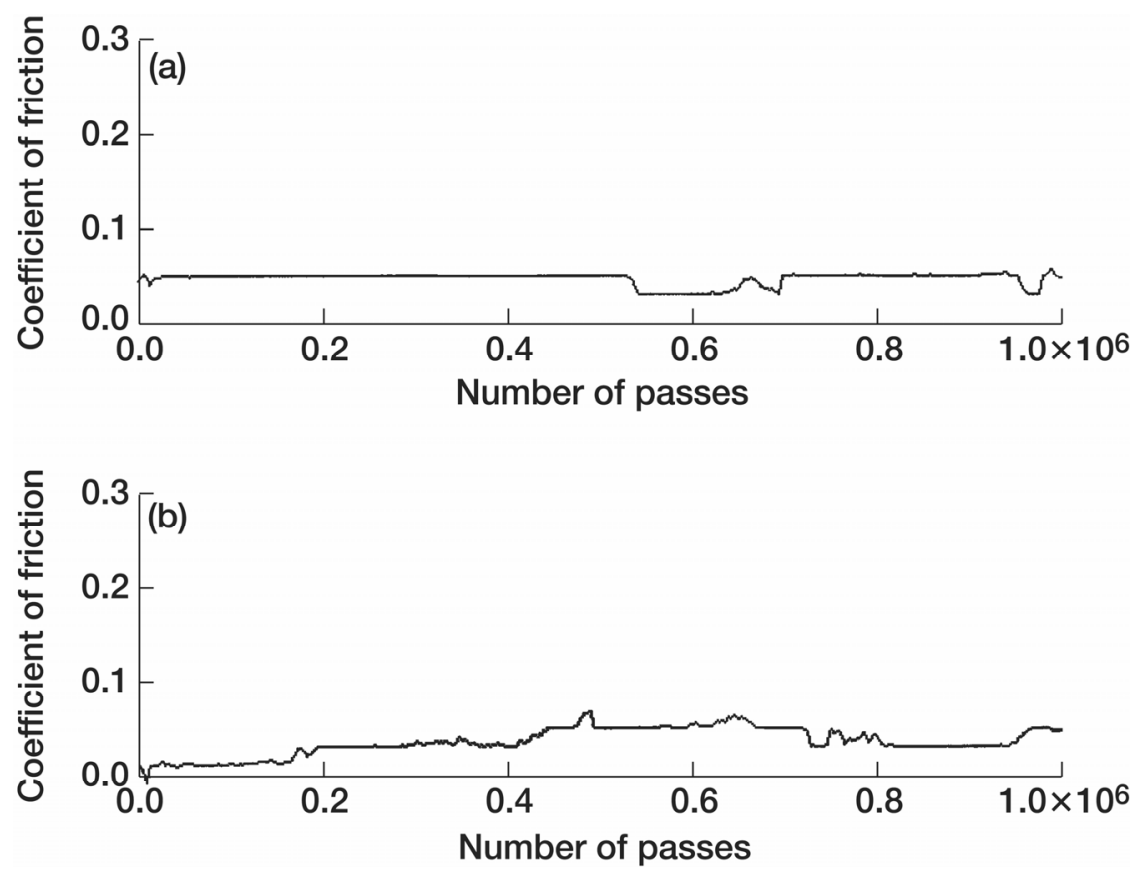

Figure 14.-Coefficient of friction traces for dispersed MWNT coatings (MWNT/quartz) in sliding contact with Al-YSZ hemispherical pins as a function of number of passes. (a) Nongraphitized MWNT coating in air. (b) Graphitized MWNT coating in ultrahigh vacuum.

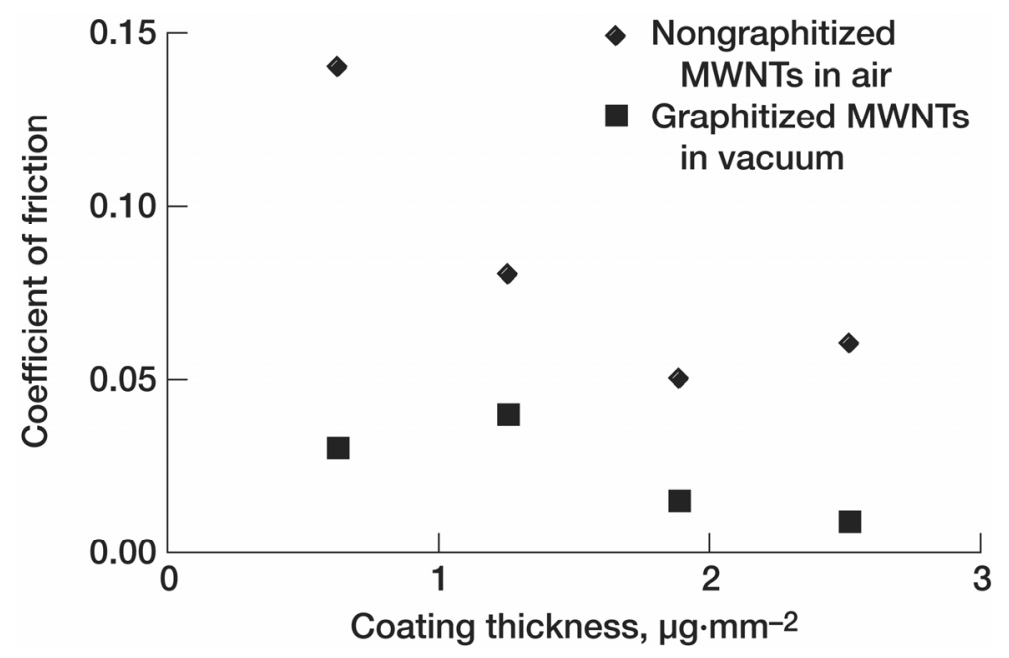

Figure 15.-Coefficient of friction traces for dispersed MWNT coatings (MWNT/quartz) in sliding contact with Al-YSZ hemispherical pins as a function of coating thickness.

vacuum, the steady-state $\mathrm{CoF}$ for the dispersed, graphitized MWNT coating with a coating thickness of $2.52 \mu \mathrm{g} \cdot \mathrm{mm}^{-2}$ showed several phases of frictional evolution; the average CoF was 0.009 in the first phase, 0.027 in the second phase, 0.044 in the third phase, and 0.027 in the fourth phase over 1 million passes. The wear life of this particular MWNT coating was greater than 1 million passes.

Figure 15 presents the steady-state coefficients of friction for the dispersed, nongraphitized MWNTs and the dispersed, graphitized MWNTs in sliding contact with Al-YSZ obtained in humid air and in ultrahigh vacuum, respectively, as a function of coating thickness. Although the relationship between CoF 
and coating thickness was not consistent, an increase in coating thickness generally resulted in a decrease in $\mathrm{CoF}$ and an increase in wear life. All dispersed MWNT coatings of each thickness tested with Al-YSZ in either air or ultrahigh vacuum met the friction criterion.

Comparison of Aligned and Dispersed MWNTs. - The dispersed, graphitized MWNT coating (fig. 14 (b)) exhibited better friction and wear life performance than those of the aligned MWNTs (fig. 13 (a)) in ultrahigh vacuum. The CoF for the dispersed, graphitized MWNTs was one-tenth of that for the aligned MWNTs, while the wear life was at least 175 times greater. The dispersed MWNT coating is superior to the aligned MWNT coating. The results indicate that prearranged or prepatterned nanostructure, such as that of the aligned MWNT coating, is not necessary for MWNTs to provide a low $\mathrm{CoF}$, that is, solid-film lubrication.

\section{Wear Surfaces}

Aligned MWNTs.-Figure 16 presents scanning electron micrographs for (a) a wear surface of the aligned MWNT coating, worn in air by a sliding 440C stainless steel ball, that reveals a smooth, burnished appearance and (b) a wear scar on the counterpart 440C stainless steel ball revealing a large amount of transferred MWNTs. The fine tubular MWNT particles (fig. 8) were flattened and burnished in the sliding direction by sliding action, leaving the smooth, burnished appearance of smeared, agglomerated MWNT layers. The large transferred plate-like, smeared, agglomerated patches of MWNTs were mostly found at the edges of the wear scar. Although the wear scar contained such transferred MWNT patches, it revealed almost no wear of $440 \mathrm{C}$ stainless steel and quartz themselves even after 100,000 passes.

Figures 17 to 19 present HRTEMs for a set of wear-debris samples collected from the wear track of an aligned MWNT coating batch. These samples represent increasing durations of sliding friction for the aligned MWNT coating. Many MWNTs were observed to be cut or broken in the sample with the shortest sliding duration (fig. 17). The predominant fraction of such structures, particularly when compared to the nascent aligned MWNTs prior to sliding friction experiments, indicates their destruction during the sliding. As such, they represent nanolubricant degradation products. Notably the high resolution images show that while the tubular structure remains, the walls are highly fragmented into many short graphene lamellas. This evolution, particularly in light of the high degree of graphitization of the nascent aligned MWNTs, suggests that the wear mechanism occurs via crushing of the tubes resulting in the extensive fragmentation of the walls. It is believed that this is a precursor stage to their complete disintegration.

As shown in figure 18, the sample representing an intermediate sliding duration exhibits similar characteristics, namely cut (or broken) MWNTs. The images reveal an amorphous carbon coating upon the exterior of the MWNTs. The origin may be the severe degradation of some portion of the aligned MWNTs. Notably the aligned MWNT containing the metal catalyst fragment retained its graphitic
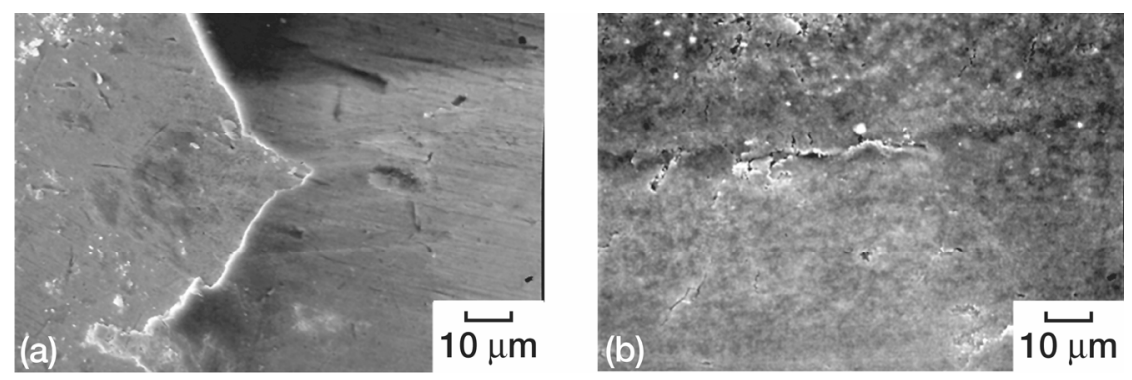

Figure 16.-Scanning electron micrographs of aligned MWNT coating. (a) Wear surface of MWNT coating after contact with $440 \mathrm{C}$ stainless steel ball counterpart. (b) MWNT patches in wear scar on 440C stainless steel ball. 

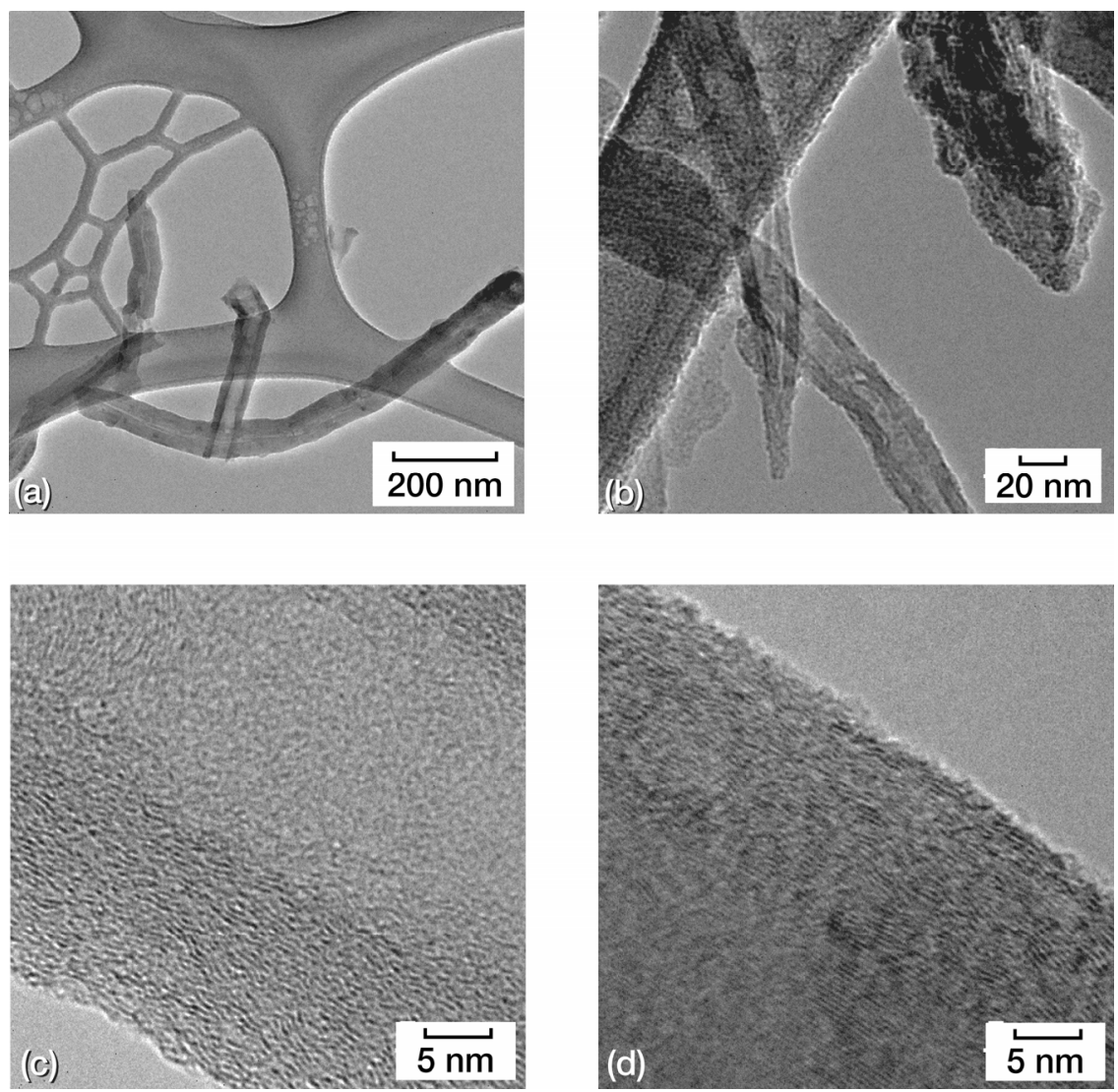

Figure 17.-Postwear analysis high-resolution transmission electron micrographs of sample collected from wear track of aligned MWNT coating after sliding friction experiment of short duration.
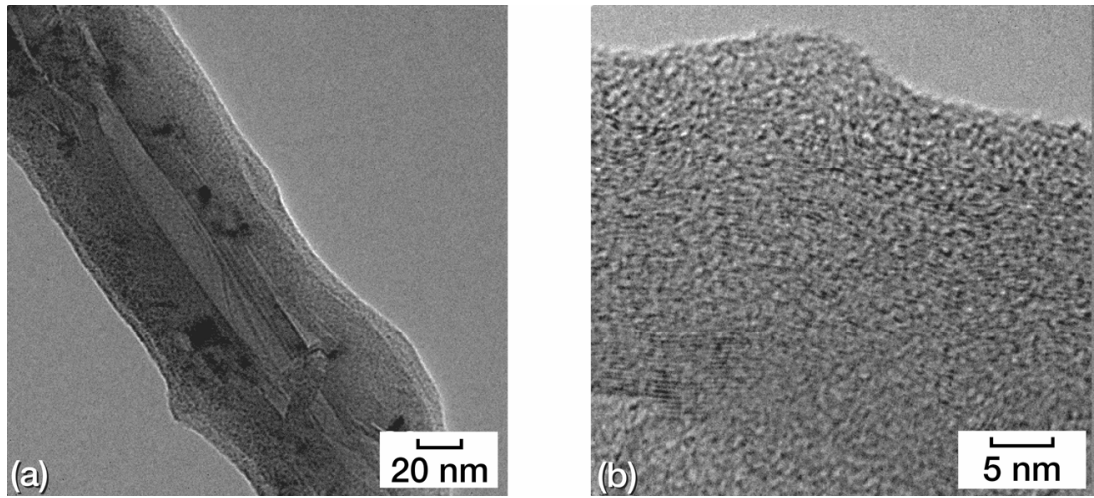

Figure 18.-Postwear analysis high-resolution transmission electron micrographs of sample collected from wear track of aligned MWNT coating after sliding friction experiment of intermediate duration.

structure. This observation, in concert with the coating that underwent the shorter sliding duration, suggests that the degradation of the MWNTs occurs via crushing, where the graphitic walls become increasingly fragmented during the course of the experiment. The net result is eventual disintegration of some MWNTs whose reformed, amorphous carbon coats the remaining intact MWNTs. Similar observations of cut MWNTs, intact tubes with highly fragmented walls, and tubes with an amorphous carbon coating were observed in the sample that underwent the longest sliding duration (fig. 19); it is 

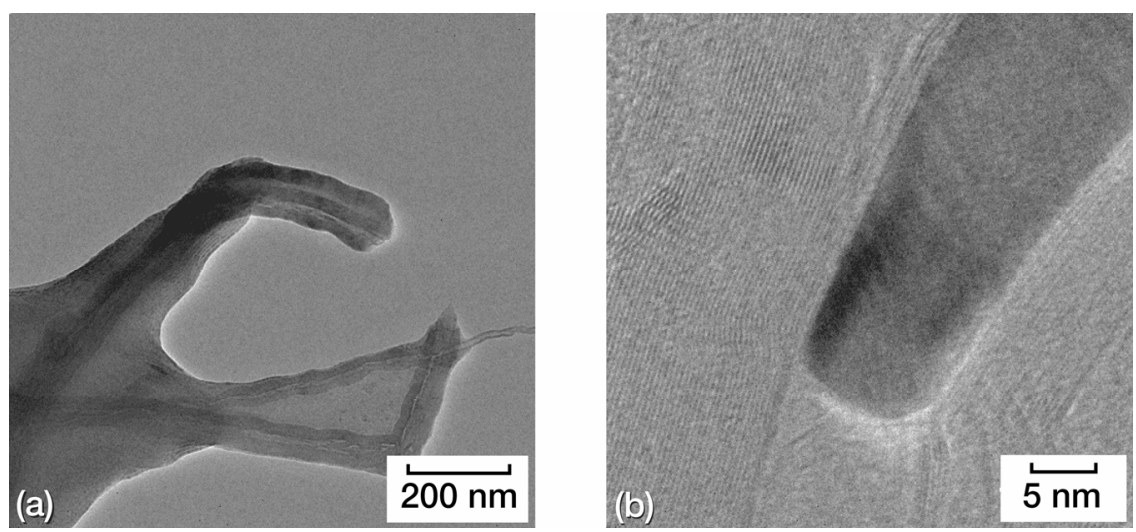

Figure 19.-Postwear analysis high-resolution transmission electron micrographs of sample collected from wear track of aligned MWNT coating after sliding friction experiment of long duration.
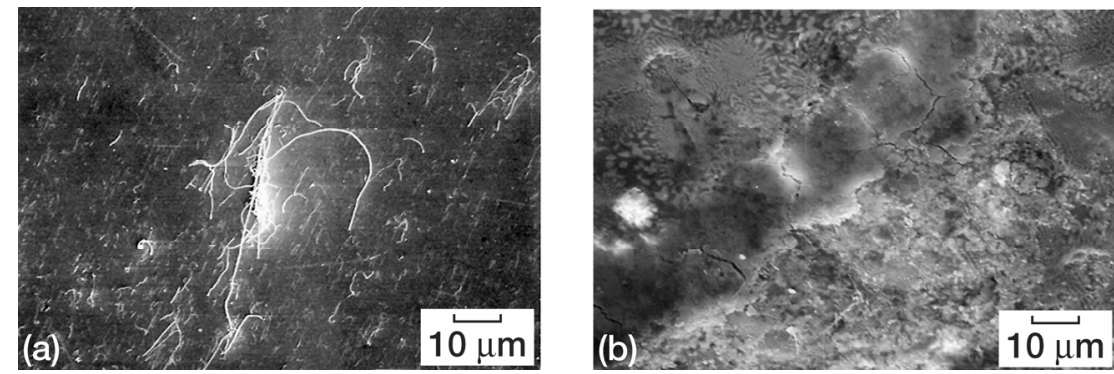

Figure 20.--Scanning electron micrographs of dispersed nongraphitized MWNT coating after contact with Al-YSZ pin counterpart in air. (a) Wear surface of MWNT coating. (b) MWNT patches in wear scar on Al-YSZ pin.

noted that this structure is comparable to that of the as-synthesized nongraphitized dispersed MWNTs in figure 10.

The HRTEM images are consistent with an increase of duration of experimental sliding time in that they show an increasing amount of amorphous carbon, cut MWNTs, and MWNTs with fractured walls as generated by the increased sliding friction duration. The plastic deformation and cracks subdivide and fragment the multi-walled structure of MWNTs. The nature of the strain or structural surface damage of MWNTs varies with depth from the surface. The thickness of the deformed layer and degree of deformation in the multi-walls are functions of the duration of sliding friction.

Dispersed MWNTs. - Figure 20 presents SEM images for (a) a wear surface of the dispersed, nongraphitized MWNT coating, worn in air by a hemispherical Al-YSZ pin, that appears curled, with segments that are submicron to tens of microns long, with MWNT cylinders in the wear track on the quartz disk and (b) a wear scar on the counterpart Al-YSZ pin revealing large transferred MWNT patches. Although most fine MWNT cylinders were plowed out and piled at both sides of the wear track, a small amount of MWNTs were cut or broken by sliding action and remained in the wear track. The smeared, agglomerated MWNT layers seen in the wear track of the aligned MWNT coating (fig. 16 (a)) are absent from the dispersed, nongraphitized MWNTs (fig. 20 (a)). The transferred plate-like, smeared, agglomerated patches of MWNTs in figure 16(a) were found in the wear scar and at the edges of the wear scar. Although the wear scars on the 440C stainless steel and Al-YSZ contained such transferred MWNT patches, both revealed almost no wear.

Figure 21 presents SEM images for (a) a wear surface of the dispersed, graphitized MWNT coating, worn in ultrahigh vacuum by a hemispherical Al-YSZ pin, that shows agglomerated MWNT patches and particles in the wear track on the quartz disk and (b) a wear scar on the counterpart Al-YSZ pin revealing 

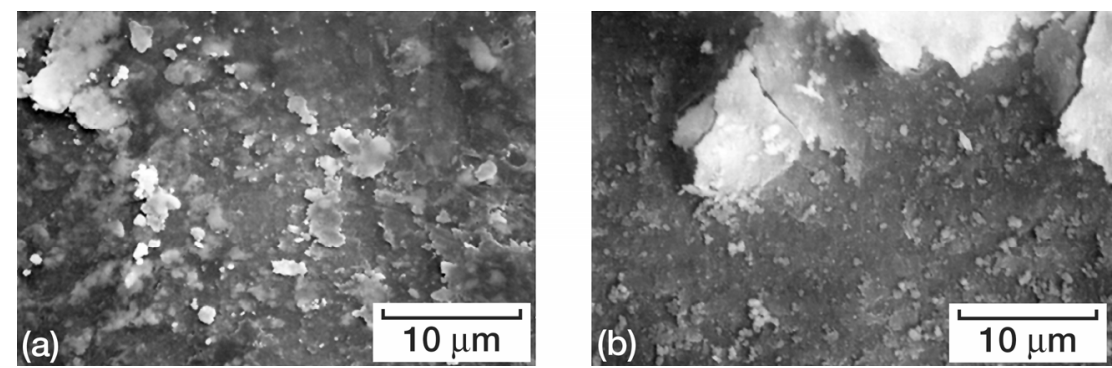

Figure 21.-Scanning electron micrographs of dispersed graphitized MWNT coating. (a) Wear surface of MWNT coating after contact with Al-YSZ pin counterpart in ultrahigh vacuum. (b) MWNT patches in wear scar on Al-YSZ pin.

large transferred MWNT patches. The fine nongraphitized MWNT cylinders in the wear track obtained in air (fig. 20 (a)) are absent from the wear track of the dispersed, graphitized MWNTs (fig. 21 (a)). The smeared, agglomerated patches of MWNTs transferred to the Al-YSZ were found in the wear scar and at the edges of the wear scar. Although the wear scar contained such transferred MWNT wear patches, it revealed almost no wear of Al-YSZ. Both the surfaces of the quartz disk and Al-YSZ pin were covered with agglomerated patches of MWNTs and were protected from wear because of no direct contact between these surfaces.

\section{Solid Lubrication Mechanisms of MWNTs}

Examining the friction and wear behavior of the MWNTs provided detailed information about friction properties, deformation, wear debris, and transferred wear fragments of MWNTs during sliding. The presence of a thin transfer film provided a low CoF. The presence of the MWNT cylinders in the wear track, in which amorphous carbon layers were formed upon the exterior of the MWNTs during sliding, also contributed to the CoF. In general, the low $\mathrm{CoF}$ can be attributed to the combination of the transfer film and/or tubular MWNTs. Based on the experimental results, the following solid lubrication mechanisms can be postulated:

Aligned MWNTs. - When an aligned-MWNT-coated quartz disk (MWNT/Fe/quartz) is brought into contact with a smooth rounded surface of 440C stainless steel or Al-YSZ ceramic, three factors contribute toward reducing the CoF: 1) Direct contact between the quartz or iron and the 440C stainless steel or AlYSZ is avoided by agglomerated patches of MWNTs. 2) The shear strength and the surface energy of the interface (Miyoshi 1998 and 2001) is minimized by agglomerated patches of MWNTs. 3) The real area of contact (Miyoshi 1998 and 2001) is minimized because of the high elastic moduli of the MWNTs, AlYSZ, and quartz.

Dispersed MWNTs.-When a dispersed MWNT coating on quartz disk (MWNT/quartz) is brought into contact with a smooth, rounded surface of Al-YSZ ceramic, three factors are contributing toward reducing the CoF: 1) Friction resistance is minimized by the rolling motion of the cut or broken MWNTs and the short graphene lamellae in the wear track. 2) The real area of contact is minimized by the high elastic modulus of the MWNTs, Al-YSZ, and quartz. 3) The surface energy at the interface is minimized by the residual MWNTs.

\section{Conclusions on MWNT Tribology}

To evaluate recently developed aligned MWNT coatings and dispersed MWNT coatings for solidfilm lubrication applications, unidirectional sliding friction experiments were conducted with the MWNTs in sliding contact with hemispherical Al-YSZ ceramic pins and 440C stainless steel balls in air and in ultrahigh vacuum. The main criterion for evaluating the solid-film lubrication performance of the 
materials was the $\mathrm{CoF}$, which had to be less than 0.15 in a given environment. The following conclusions were drawn:

1. MWNTs met the friction criterion and had superior friction properties and endurance lives in air or ultrahigh vacuum under dry conditions. The CoF of MWNTs is close to 0.05 and 0.009 in air and in ultrahigh vacuum, respectively. The wear life of MWNTs exceeds 1 million passes in air and in ultrahigh vacuum showing good durability.

2. Prearranged or prepatterned nanostructure, such as in the aligned MWNT coating, is not necessary for MWNTs to provide solid-film lubrication. The dispersed MWNT coating is superior to the aligned MWNT coating.

3. Three factors contribute toward reducing the $\mathrm{CoF}$ and providing a good, durable performance of the MWNT coating: a) Friction resistance is minimized by the cut or broken MWNTs and the short graphene lamellae in the wear track. b) The real area of contact is minimized by the high elastic modulus of the MWNTs, Al-YSZ, and quartz. c) The surface energy at the interface is minimized by the residual MWNTs.

\section{Single-walled and Surface Fluorinated Nanotube Investigations}

\section{Background and Objectives}

The performance of solid lubricants largely depends upon the particle size and their shape at the nanoscale level (Glaeser, 1993, Lansdown, 1996, Summers-Smith, 1994 and Tenne, et al., 1998). Modeling and experimental studies suggest that the cage-like nanosize particles having either spherical or tubular morphology will provide great application advantages in the field of tribology (Tenne, et al., 1998). Their seamless structure helps to inhibit the sticking and burnishing of the nanoparticles by the rubbing metal or other surfaces. These tubular particles may slide and roll in part during sliding contact, resulting in low friction and wear. The primary structures may also crack open during contact between the tribocouples leading to small graphitic low surface energy layers which behave similar to graphite. The spherical nanoparticles also can serve as effective spacers, prohibiting contact and wear of the metal surfaces under heavy loads where fluid lubricants are normally squeezed out. Other advantages include the superior oxidation and thermal stability of the tubular and spherical nanoparticles, prolonging their wear life. For example, as mentioned in the section on CNO Tribology, the 0.04 to $0.05 \mathrm{CoF}$ obtained with the $\mathrm{CNO} /$ Krytox mixture in air was attributed to the $\mathrm{CNO}$, which is well below the typical reported values for graphite of 0.13 to 0.3 (Pierson, 1993) or the Krytox oil.

The discovery of synthetic methods to produce CNTs, structurally built of graphene cylinders, opened the research opportunities for a variety of applications, including lubricants. Surface modification of the CNTs as well as other carbon nanoparticles, CNOs (Street, et al., 2004) and nanodiamonds (Dolmatov, 2001), through chemical treatment (Khabashesku and Margrave, 2004), e.g., fluorination (Liu, et al., 2004 and Khabashesku, et al., 2002), is expected to affect their friction and degradation behavior in lubricant applications. This expectation is supported by the experimental studies of graphite fluoride $(\mathrm{CF})_{\mathrm{x}}$ powder films that demonstrate longer wear lives, low $\mathrm{CoF}$ and superior load-carrying capacities in comparison with graphite both in humid air and at elevated temperatures due to weakened interlamellar van der Waals' forces (Gisser, et al., 1972, and Kamarchi and Margrave, 1978). The intent of this work is to examine the effect of surface modification of SWNTs on their tribological properties. Reported below is the evaluation data on $\mathrm{CoF}$ and wear life of neat lubricating films prepared from SWNT and fluorinated SWNT, "fluoronanotubes," with variable $C_{n} F(n=2-20)$ stoichiometry. Samples of pristine and oxidative acid treated nanotubes, and the nanotubes which were short-cut by the fluorination-pyrolysis method $(\mathrm{Gu}$, et al., 2002) were also tested for comparison. 


\section{Nano- and Microstructure of SWNTs}

High resolution TEM images (fig. 22) show significantly different surface morphologies for all chemically treated nanotube samples in comparison with the pristine SWNTs. The SWNT form bundles of different diameter due to the random nature of the way they are collected and mounted. These bundles are held together by strong wall-to-wall van der Waals' forces.

Smooth sidewall surfaces of thick SWNT bundles (fig. 22(a)) generate slight protrusions as a result of oxidative acid $\left(\mathrm{HNO}_{3}\right)$ treatment under mild conditions which creates minor defects on the sidewalls of nanotubes, cuts them into shorter lengths and opens their ends, as shown by the image of a cut-SWNT sample in figure 22(b). Fluorination causes more dramatic changes in SWNT surface appearance by increasing both the size and number of protrusions on the sidewalls of nanotubes in $\mathrm{C}_{2} \mathrm{~F}$ and $\mathrm{C}_{5} \mathrm{~F}$ samples
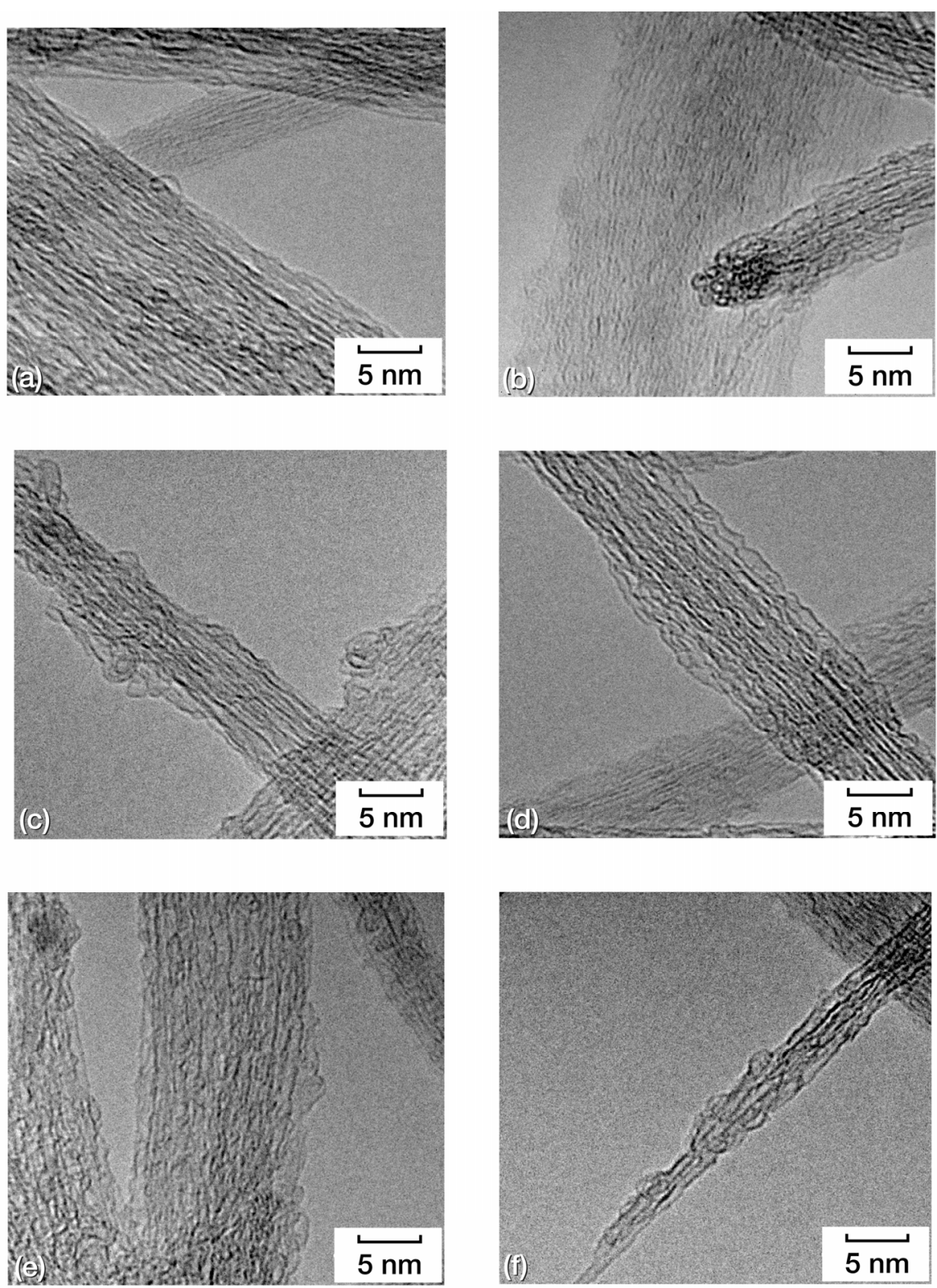

Figure 22.-High-resolution transmission electron micrographs of SWNT samples studied. (a) Nascent SWNTs. (b) cut-SWNTs. (c) $\mathrm{C}_{2} \mathrm{~F}$ Stoichiometry. (d) $\mathrm{C}_{5} \mathrm{~F}$ Stoichiometry. (e) $\mathrm{C}_{20} \mathrm{~F}$ Stoichiometry. (f) F-cut-SWNTs. 
(fig. 22 (c) and (d)) that can be related to a great number of $\mathrm{sp}^{3}$ carbon-carbon bonds formed via the sidewall functionalization (Khabashesku and Margrave, 2004, and Liu, et al., 2004). Significant reduction in bundle size is also noted for these fluoronanotubes.

Treatment of the $\mathrm{C}_{2} \mathrm{~F}$ sample with hydrazine helps to remove fluorine without causing any significant destruction to the sidewalls of nanotubes in the resulting $\mathrm{C}_{20} \mathrm{~F}$ sample. The TEM image (fig. 22(e)) of this sample shows a largely restored smooth surface morphology, as in pristine SWNTs. In contrast with this sample, some surface areas of F-cut-SWNT (fig. 22(f)), are partially damaged and appear as split open tubes. This can be correlated with the persistent showing of the sidewall "defect" mode in the Raman spectra of nanotubes cut by fluorination (Gu, et al., 2002).

\section{Tribology of SWNTS}

The CoF determined for all tested neat nanotube samples at four relative disk coating thicknesses are summarized in figure 23. These data show that almost all measured CoF lie well below the published range of values for graphite of 0.13 to 0.3 (Pierson, 1993), the most commonly used solid lubricant in air environment, with the exception of only a very few values falling into a low vicinity of this range. This clearly indicates that all tested SWNT samples exhibit very good friction properties. However, for most samples tested the relationship between $\mathrm{CoF}$ and coating thicknesses was found to be inconsistent.

Thus, in the case of pristine SWNTs a steady increase in coating thickness results in consistent lowering of the CoF, while similar increases in coating thickness for cut-SWNTs cause negligible effect, always yielding a $\mathrm{CoF}$ as low as 0.07 to 0.09 . A steady decrease of friction coefficient is observed for fluoronanotubes $\mathrm{C}_{2} \mathrm{~F}$ and $\mathrm{C}_{20} \mathrm{~F}$ samples with increase in coating level from 0.63 to $1.89 \mu \mathrm{g} / \mathrm{mm}^{2}$. At the highest coating level $\left(2.52 \mu \mathrm{g} / \mathrm{mm}^{2}\right)$ for $\mathrm{C}_{2} \mathrm{~F}$ and $\mathrm{C}_{20} \mathrm{~F}$ and at $1.89 \mu \mathrm{g} / \mathrm{mm}^{2}$ for F-cut-SWNTs, the friction coefficient again increases. The $\mathrm{C}_{5} \mathrm{~F}$ samples demonstrate a very low friction $(0.02$ to 0.05$)$ at $0.63,1.26$, and $2.52 \mu \mathrm{g} / \mathrm{mm}^{2}$ thicknesses, but show an elevated value $(0.2)$ at $1.89 \mu \mathrm{g} / \mathrm{mm}^{2}$. The observed discrepancy is likely related to the difficulty in applying a uniform coating of the nano materials onto the disk in some experiments.

Nevertheless, the measured lowest CoF for SWNT samples in air (fig. 24) were found to either fall into the range known for the best lubricants, such as DLC (0.05 to 0.15) and Teflon (0.03 to 0.1), or even outperform the latter. For instance, F-cut-SWNTs and $\mathrm{C}_{5} \mathrm{~F}$ samples show very low values of 0.013 and 0.016 , respectively, pristine SWNTs -0.011 , while a $\mathrm{C}_{20} \mathrm{~F}$ sample yields an ultra-low friction coefficient

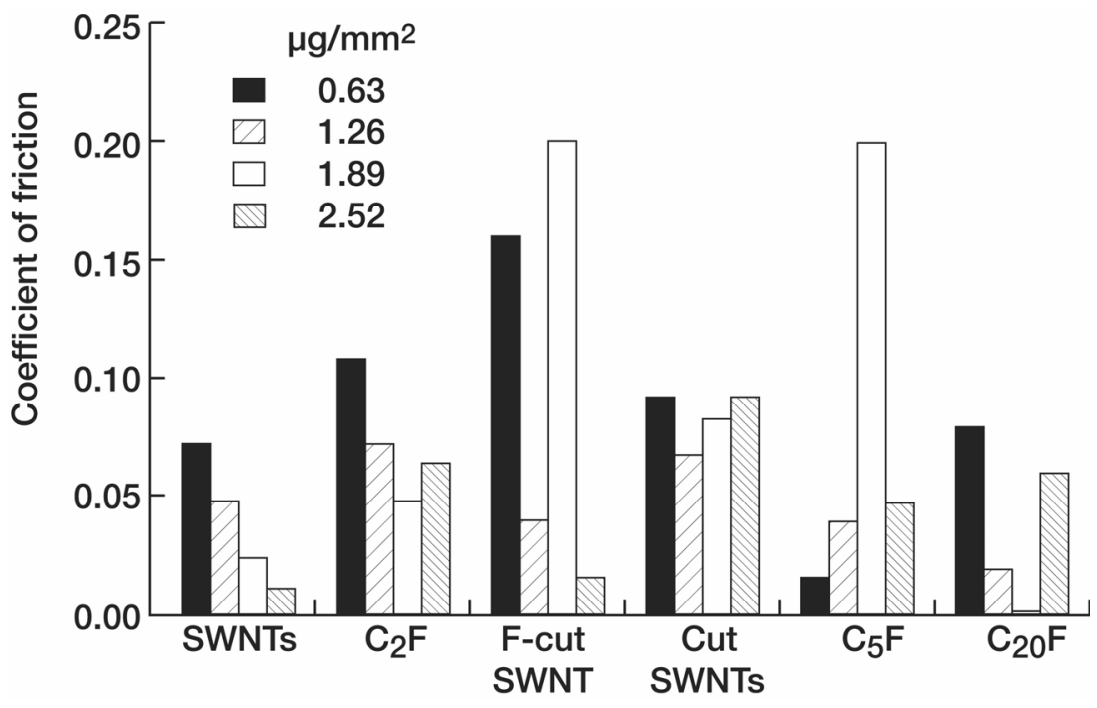

Figure 23.-Friction coefficients of SWNT samples determined at different relative coating thickness in contact with sapphire in air. 


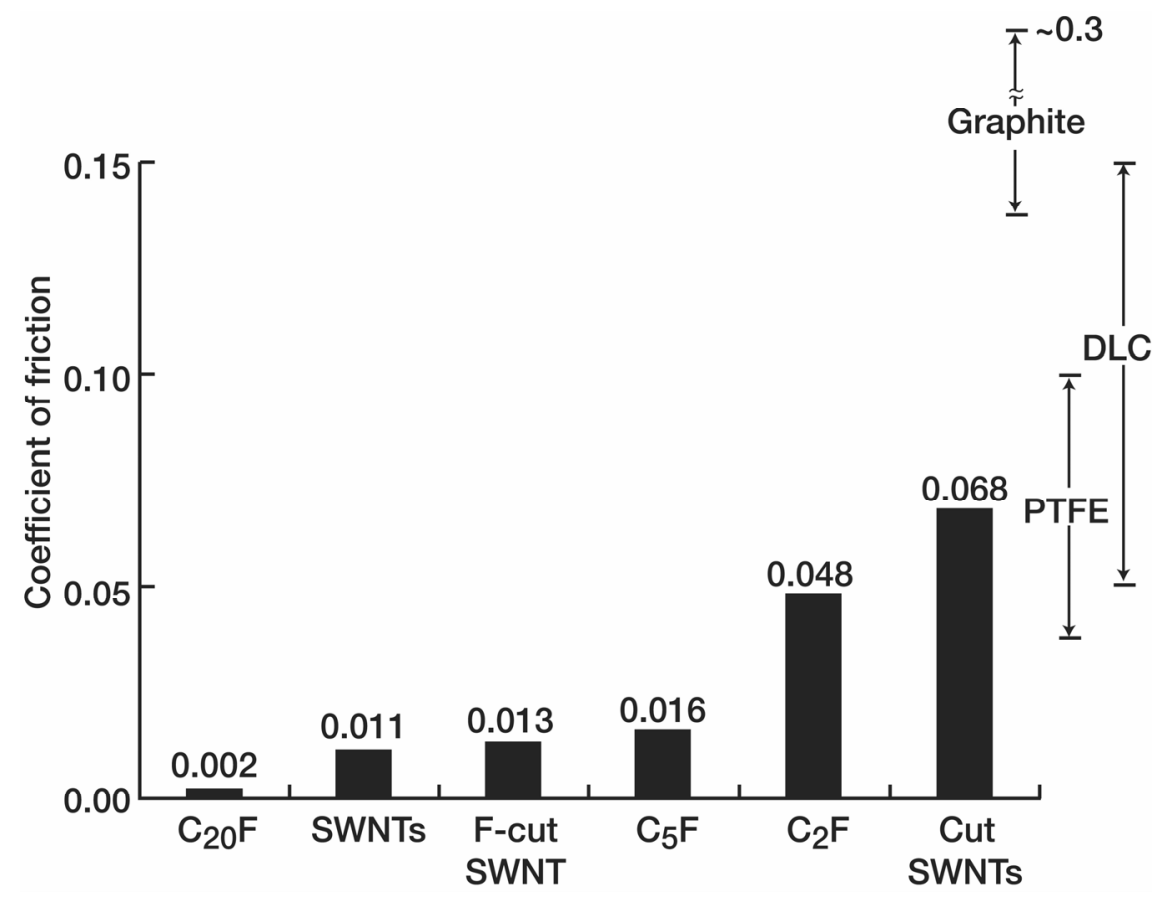

Figure 24.-Lowest friction coefficients determined for SWNT samples in contact with sapphire in air.

of 0.002. It is likely that the lowest friction shown by these four SWNT samples in a humid air environment can be related both to the smooth (or relatively smooth) sidewall surface morphology and to the drastically increased surface area in the case of very short F-cut-SWNTs. It also appears that having a small amount of residual fluorine on the sidewall of the nanotube assists in obtaining an ultra-low friction, as observed for $\mathrm{C}_{20} \mathrm{~F}$ (0.002). Finally, as figures 23 and 24 show, all materials tested exhibit $\mathrm{CoF}$ substantially lower than traditional carbon materials and generally better than DLC films. The SEM observations of the wear tracks indicated that although most nanotubes were generally plowed out and piled at both sides of the wear track, a small amount of tubular particles remained in the wear track.

The measured relative order of CoF can be understood on the basis of material composition. By reference to bulk materials, fluorination can improve the lubricity of carbon materials. Yet fluorination can introduce "defects" within the SWNT sidewalls. These defects may result in premature degradation of the material (tubular structure) and corresponding loss of lubrication. Upon degradation, reactive edge sites will be created leading to binding between the lubricant and adjacent surfaces. Furthermore, $\mathrm{sp}^{3}$ hybridization of sidewall carbons will reduce the flexibility, modulus and tensile strength of the SWNT. Hence a lower degree of fluorination may provide a more resilient material, better able to resist buckling than a more highly fluorinated material. Notably this stands in contrast to bulk materials and arises from the nanosize scale of these lubricants. A second consideration is that fluorination will act to separate tubes within bundles. While some separation may be desirable, it is possible that individual SWNTs may not be best because surface roughness exceeds their diameter. Hence they cannot prevent contact between surface asperities like MWNT and CNO. Moreover, tubes within bundles permit the possibility of intertube sliding whereas single SWNTs necessarily slide between adjacent tribological surfaces.

Under the conditions studied, the highest endurance or wear life was demonstrated by the pristine SWNT sample (fig. 25). This was followed by the $\mathrm{C}_{20} \mathrm{~F}$ and F-cut-SWNT materials. The other three nanotube samples show much lower wear lives as lubricants. These data show that the wear lifetimes exhibit a roughly inverse correlation with $\mathrm{CoF}$ : lower friction coefficient correlates with longer lubrication lifetime. Interestingly, the $\mathrm{C}_{20} \mathrm{~F}$ material shows a lifetime a bit lower than the pristine SWNTs. This can be understood on the basis of the fluorination introducing defects, namely $\mathrm{sp}^{3}$ hybridization sites 


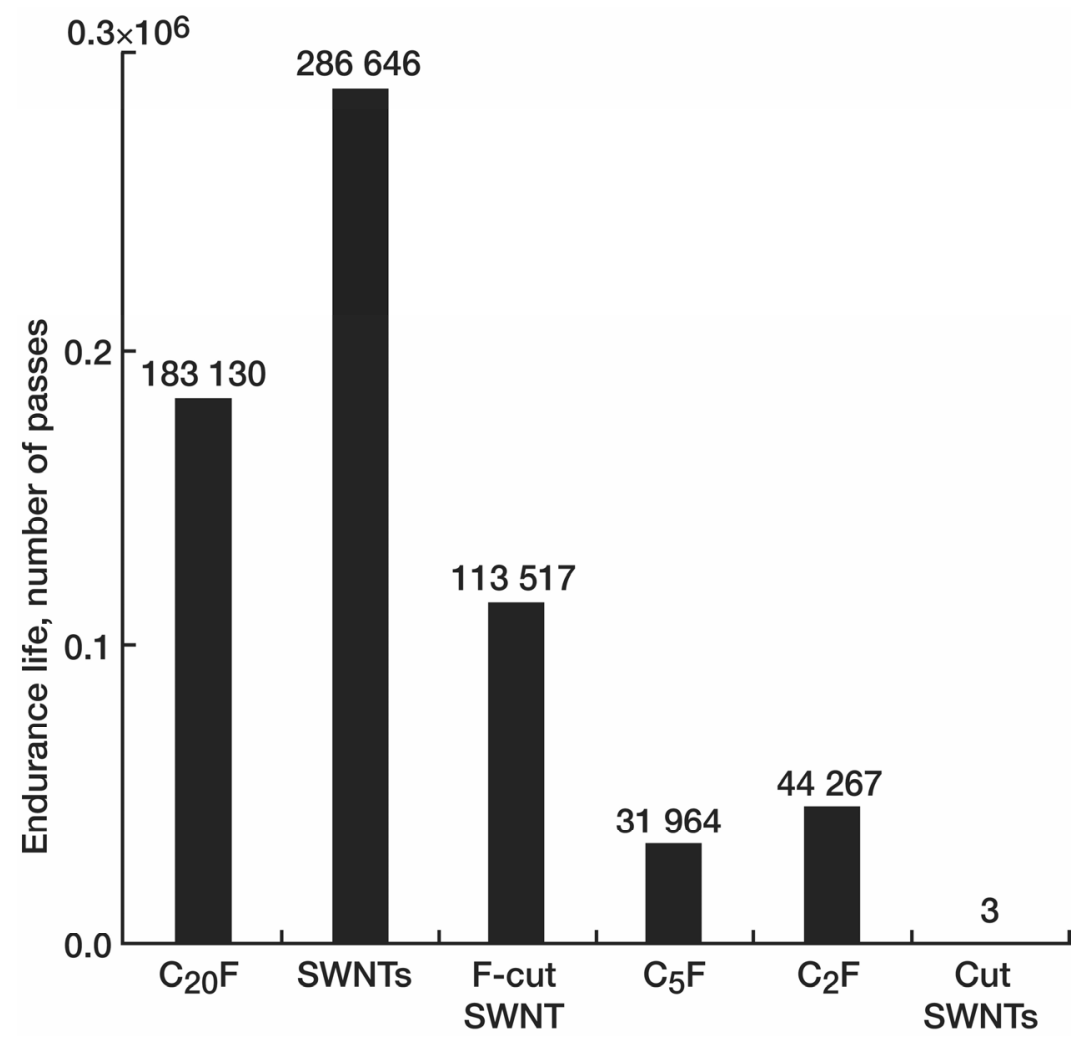

Figure 25.-Endurance (wear) life for SWNT lubricating coatings in contact with sapphire in air.

within the SWNT sidewalls. These sites disrupt the integrity of the aromatic framework and create sites where buckling or other degradation can occur. The modest amount of $\mathrm{F}$ in the $\mathrm{C}_{20} \mathrm{~F}$ material results in its performance having somewhat less duration than the SWNT material. Notably, it has a longer wear life than any of the other fluorinated materials, all of which possess a higher $\mathrm{F}$ : C stoichiometry. Increasing $\mathrm{F}$ content necessarily introduces larger amounts of wall disruption, hastening degradation and shortening lubricant lifetime.

While the F-cut-SWNT materials nominally have the same composition as the $\mathrm{C}_{5} \mathrm{~F}$ materials, their smaller length may aid lubrication. As they are produced by pyrolysis, the tube ends are expected to be closed by either bonding to adjacent carbon or the carbon atoms are terminated by $-\mathrm{F}$ or $-\mathrm{H}$ atoms. Notably, these groups are more thermodynamically stable than oxygen containing functional groups. For the cut SWNTs, the cutting action has been shown to introduce significant amounts of oxygen containing functional groups at the tube ends, terminating the carbon valencies. Apart from their reactivity, these groups can readily oxidize the SWNT ends during friction testing, thereby degrading the lubricant. Moreover, upon oxidation, radical sites will be created that will cause stiction with adjacent surfaces, thereby accounting for the relatively high friction coefficient.

\section{Conclusions on SWNT Tribology}

Tribological studies of a series of SWNT samples in air revealed that the type of chemical treatment of nanotube surface has a significant effect on their lubrication properties. The $\mathrm{CoF}$ for fluoronanotubes, as well as pristine and chemically cut nanotubes, were found to reach values as low as 0.002 to 0.07 , thus showing a promise for application of surface modified SWNTs as solid lubricants. Based on combined friction and wear life data, pristine SWNTs and $\mathrm{C}_{20} \mathrm{~F}$ samples show the best lubrication performance in air among all SWNT samples investigated thus far. 
We interpret the trend in SWNT materials as lubricants being partly related to the degree to which they can fill in pits and scratches, and between surface asperities, etc. between sliding surfaces. If this were the only mechanism, then all tubes would behave similarly; hence there are additional effects from the chemical nature of the surface modifications. A modest amount of fluorination can serve to break up SWNT bundles, without significant tube wall degradation, thereby creating a better lubricant. While cut SWNTs and F-cut-SWNTs should similarly have tube segments commensurate with surface roughness values, their production alters the graphitic quality of the SWNTs (on the tube ends), leading to a poorer lubricating ability. Magnifying this trend is the higher fluorination stoichiometry of the $\mathrm{C}_{2} \mathrm{~F}$ and $\mathrm{C}_{5} \mathrm{~F}$ materials. Though producing a nominally better lubricant by reference to bulk materials, their synthesis leads to substantial SWNT degradation (by introduction of $\mathrm{sp}^{3}$ hybridization, etc.). Consequently these highly fluorinated SWNTs can be less resilient towards deformation and more apt to rupture, producing dangling bonds and resulting stiction.

\section{Concluding Remarks}

While CNT and CNO have not enjoyed commercialization like other carbon materials such as DLC and GLC, the nanomaterials possess distinct advantages that will eventually lead to commercialization. A major problem in this field has been the expense of materials, driven by the manner of synthesis and requirements of further purification for the CNT. Development of inexpensive, commercially feasible, industrial scale production processes for $\mathrm{CNO}$, on the other hand, are close to realization. A second problem for developing applications is the difference between nano materials obtained from different processes described by various researchers in the field, a problem which will be overcome by commercial production of these materials. In our efforts at Glenn Research Center, we have relied on numerous suppliers of MWNT and SWNT, and have developed the technology to produce large quantities of pure, high-quality CNO. As can be seen in report, publication, NASA/TM-2007-214473, the conditions for successful deployment of these nano structured materials is highly dependent on the environment, the tribocouples involved and the nanomaterials employed. With proper choice of system, it is possible to obtain ultra low friction and long wear life. These materials would then appear to be reasonable choices to consider for replacing graphite, one of the most widely used solid lubricants.

\section{References}

Braithwaite, E.R., 1964. Solid lubricants and surfaces, Pergamon Press, New York (Chapter 5).

Chiang, I.W., Brinson, B.E., Huang, A.Y., Willis, P.A., Bronikowski, M.J., Margrave, J.L., Smalley, R.E., and Hauge, R.H., 2001. Purification and characterization of single-wall carbon nanotubes (SWNTs) obtained from the gas-phase decomposition of CO (HiPco Process). J. Phys. Chem. B 105: 8297-8301.

Davis, K.A., Hurt, R.H., Yang, N.Y., and Headley, T.J., 1995. Evolution of Char Chemistry, Crystallinity, and Ultrafine Structure during Pulverized-Coal Combustion. Combust and Flame 100: 31-40.

Dolmatov, V.Yu., 2001. Detonation synthesis of ultradispersed diamonds: properties and applications, Russ. Chem. Revs. 70: 607-626.

Donnet, J.B., Bansal, R.C., and Wang, M.-J., 1993. Carbon black science and technology, 2nd ed., Marcel Dekker, Inc., New York.

Fernandez-Palacio, J., Arce-Garcia, I., and Bull, S.J., 2004. Indentation response of fullerene-like CNx. in "Novel carbons in tribology," eds. Miyoshi, K., and Street, K.W., Tribology International 37(11-12): 929-940.

Gisser, H., Petronio, M., and Shapiro, A., 1972. Graphite Fluoride as a Solid Lubricant, Lubr. Eng. 28: 161-164.

Glaeser, W.A., 1993. Characterization of Tribological Materials, Butterworth- Heinemann, Boston (p. 1).

Gu, Z., Peng, H., Hauge, R.H., Smalley, R.E., and Margrave, J.L., 2002. Cutting single-wall carbon nanotubes through fluorination. Nano Lett. 2: 1009-1013. 
Gu, Z., Zhang, L., Margrave, J.L., Davydov, V.A., Rakhmanina, A.V., Agafonov, V., Khabashesku, V.N., 2005. Fluorination of pressure-polymerized C60 phases. Carbon 43: 2989-3001.

Hirata, A., Igarashi, M., and Kaito, T., 2004. Study on Solid Lubricant Properties of Carbon Onions Produced by Heat Treatment of Diamond Clusters or Particles in "Novel carbons in tribology," eds. Miyoshi, K., and Street, K.W., Tribology International 37(11-12): 899-905.

Hirata A., and Yoshioka, N., 2004. Sliding friction properties of carbon nanotube coatings deposited by microwave plasma chemical vapor deposition. in "Novel carbons in tribology," eds. Miyoshi, K., and Street, K.W., Tribology International 37(11-12): 893-898.

Hiura, H., Ebbsen, T.W., Tanigaki, K., and Takahashi, H., 1993. Raman studies of carbon nanotubes. Chem. Phys. Lett. 202(6): 509-512.

Iijima S., 1991. Helical microtubules of graphitic carbon. Nature 354(6348): 56-58.

JolyPottuz, L., Dassenov, F., Vacher, B., Martin, J.M., and Mieno, T., 2004. Ultralow friction and wear behavior of Ni/Y-based single wall carbon nanotubes. in "Novel carbons in tribology," eds. Miyoshi, K., and Street, K.W., Tribology International 37(11-12): 1013-1018.

Kamarchik, P., and Margrave, J.L., 1978. Poly (Carbon Monofluoride), A Solid Layered Fluorocarbon. Acc. Chem. Res. 11: 296.

Khabashesku, V.N., Billups, W.E., and Margrave, J.L., 2002. Fluorination of single-wall carbon nanotubes and subsequent derivatization reactions. Acc. Chem. Res. 35: 1087-1095.

Khabashesku, V.N. and Margrave, J.L., 2004. Chemistry of carbon nanotubes, in: Encyclopedia of Nanoscience and Nanotechnology, vol.1, Ed. Nalwa, H.S., American Scientific Publishers, Stevenson Ranch, California, pp. 849-861.

Lansdown, A.R., 1996. Lubrication and Lubrication Selection. A Practical Guide, Ed. B.S. Edmunds, Mechanical Eng. Publ. Ltd., Suffolk, UK.

Liu, Y. Gu, Z. Margrave, J.L., and Khabashesku, V.N., 2004. Functionalization of Nanoscale Diamond Powder: Fluoro-, Alkyl-, Amino-, and Amino Acid-Nanodiamond Derivatives. Chem. Mater. 16: 3924-3930.

Marsh, H. 1989. Introduction to carbon science, Butterworth, London (Chapter 4).

Miyoshi, K., 1998. Lubrication by diamond and diamond like carbon coatings. J. Tribology, 120: 379-384.

Miyoshi, K., 2001. Solid lubrication fundamentals and applications. Marcel Dekker, Inc., New York, pp. 94-144.

Miyoshi, K., and Street, K.W., Jr. 2004. Novel carbons in tribology. Tribology International, 37: $865-868$.

Miyoshi, K.W. Street, K.W., Jr., Vander Wal, R.L., Andrews, R. and Sayir, A. 2005. Solid lubrication by multi-walled carbon nanotubes in air and in ultrahigh vacuum. Tribol. Lett. 19(3): 191-201.

Miyoshi, K., Vander Wal, R.L., Tomasik, A.J., Sayir, A., and Farmer, S.C., 2004. New effective material couple-oxide ceramic and carbon nanotube-developed for aerospace microsystem and micromachine technologies. NASA/TM-2004-212729. Available from http://gltrs.grc.nasa.gov.

Pepper, S.V., and Kingsbury, E.P. 2003. Spiral orbit tribometry- Part I: Description of the tribometer. Tribology Transactions 46(1): 57-64.

Pepper, S.V., and Kingsbury, E.P. 2003. Spiral Orbit tribometry- Part II: Evaluation of three liquid lubricants in vacuum. Tribology Transactions 46(11): 65-69.

Pierson, H.O., 1993. Handbook of Carbon, Graphite, Diamond and Fullerenes. Properties, Processing and Applications, Noyes, New York (Chapter 3).

Rosner, D.E., and Allendorf, H.D., 1968. Comparative studies of the attack of pyrolitic and isotropic graphite by atomic and molecular oxygen at high temperatures. AIAA Journal 6: 650-654.

Street, K.W., Marchetti, M., Vander Wal R.L., and Tomasek, A.J., 2004. Evaluation of the tribological behavior of nano-onions in Krytox 143AB. Tribol. Lett. 16(1-2): 143-149.

Street, Jr., K.W., Pepper, S.V., Wright, A., and Grady, B., 2007. Determination of lubricants on ball bearings by FT-IR using an integrating sphere NASA TM-2007-214472. 
Summers-Smith, J.D., 1994. An Introductory Guide to Industrial Tribology, Mechanical Eng. Publ. Ltd., London, UK.

Tenne, R., Homyonfer, M., and Feldman, Y., 1998. Nanoparticles of Layered Compounds with Hollow Cage Structures (Inorganic Fullerene-Like Structures). Chem. Mater. 10: 3225-3238.

Thomas, J.M., 1965. in: The chemistry and physics of carbon, vol.1, Ed. Walker, Jr., P.L., Marcel Dekker, Inc., New York (Chapter 2).

Tuinstra E., and Koenig, J., 1970. Raman spectrum of graphite. J. Chem. Phys. 53: 1126-1130.

Vander Wal, R.L., and Choi, M.Y., 1999. Pulsed laser heating of soot: morphological changes. Carbon 37(2): 231-239.

Vander Wal, R.L., Tomasek, A.J., Street, K.W., and Thompson, W.K., 2004. Carbon nanostructure examined by lattice fringe analysis of high resolution transmission electron microscopy images. Appl. Spectr. 58(2): 230-237.

Vander Wal, R.L., Miyoshi, K., Street, K.W., Tomasek, A.J., Peng, H., Liu, Y., Margrave, J.L., and Khabashesku, V.N., 2005. Friction properties of surface-fluorinated carbon nanotubes. Wear 259: 738-743.

Wan, G.T.Y., and Spikes, H.A., 1988. The behavior of suspended solid particles in rolling and sliding elastohydrodynamic contacts. Tribology Transactions 31(1): 12-21.

Wunsch, F., 1991. Synthetic fluid based lubricating greases. NLGI Spokesman 54(1): 12-22.

Yu, M.-F., Files, B.S., Arepalli, S., and Ruoff, R.S., 2000. Tensile loading of ropes of single wall carbon nanotubes and their mechanical properties. Phys. Rev. Lett. 84: 5552-5555. 
Public reporting burden for this collection of information is estimated to average 1 hour per response, including the time for reviewing instructions, searching existing data sources, gathering and maintaining the data needed, and completing and reviewing the collection of information. Send comments regarding this burden estimate or any other aspect of this collection of information, including suggestions for reducing this burden, to Washington Headquarters Services, Directorate for Information Operations and Reports, 1215 Jefferson Davis Highway, Suite 1204, Arlington, VA 22202-4302, and to the Office of Management and Budget, Paperwork Reduction Project (0704-0188), Washington, DC 20503.

\begin{tabular}{|l|l|l|}
\hline 1. AGENCY USE ONLY (Leave blank) & $\begin{array}{c}\text { 2. REPORT DATE } \\
\text { January } 2007\end{array}$ & $\begin{array}{r}\text { 3. REPORT TYPE AND DATES COVERED } \\
\text { Technical Memorandum }\end{array}$ \\
\hline
\end{tabular}

\section{TITLE AND SUBTITLE}

Application of Carbon Based Nano-materials to Aeronautics and Space Lubrication

\section{6. $\operatorname{AUTHOR(S)}$}

Kenneth W. Street, Jr., Kazuhisa Miyoshi, and Randy L. Vander Wal

\section{FUNDING NUMBERS}

WBS 984754.01.03

\section{PERFORMING ORGANIZATION NAME(S) AND ADDRESS(ES)}

National Aeronautics and Space Administration

John H. Glenn Research Center at Lewis Field

Cleveland, Ohio 44135-3191
8. PERFORMING ORGANIZATION REPORT NUMBER

E-15765

\section{SPONSORING/MONITORING AGENCY NAME(S) AND ADDRESS(ES)}

National Aeronautics and Space Administration

Washington, DC 20546-0001

10. SPONSORING/MONITORING AGENCY REPORT NUMBER

NASA TM-2007-214473

\section{SUPPLEMENTARY NOTES}

Kenneth W. Street, Jr., and Kazuhisa Miyoshi, NASA Glenn Research Center; Randy L. Vander Wal, The Universities Space Research Association, 21000 Brookpark Road, Cleveland, Ohio 44135. Responsible person, Kenneth W. Street, organization code RXT, 216-433-5032.

\section{2a. DISTRIBUTION/AVAILABILITY STATEMENT}

12b. DISTRIBUTION CODE

Unclassified - Unlimited

Subject Category: 37

Available electronically at http://gltrs.grc.nasa.gov

This publication is available from the NASA Center for AeroSpace Information, 301-621-0390.

\section{ABSTRACT (Maximum 200 words)}

The tribology program at NASA Glenn Research Center in Cleveland, Ohio, is investigating carbon based nano-particles for their potential in advanced concept lubrication products. Service conditions range from high temperature atmospheric to low temperature vacuum. Some of the lubricants and surface coatings of tribological significance that we have evaluated include neat nano-particles, both grown in-situ and as bulk material deposited on the substrate, and nano-particles dispersed in oils which are all highly substrate interactive. We discuss results of testing these systems in a spiral orbit tribometer (SOT) and a unidirectional pin-on-disc (PoD) tribometer. A nano-onions/Krytox mixture evaluated as a lubricant for angular contact bearings in air caused a marked lowering of the coefficient of friction $(\mathrm{CoF})(0.04$ to 0.05$)$ for the mixture with an eight-fold improvement in lifetime over that of the Krytox alone. In vacuum, no effect was observed from the nano-onions. Multi-walled nanotubes (MWNT) and graphitized MWNT were tested under sliding friction in both air and vacuum. The MWNT which were grown in-situ oriented normal to the sliding surface exhibited low CoF (0.04) and long wear lives. Bulk MWNT also generate low CoF (0.01 to 0.04, vacuum; and 0.06, air) and long wear life (>1 million orbits, vacuum; and $>3.5$ million, air). Dispersed graphitized MWNT were superior to MWNT and both were superior to aligned MWNT indicating that orientation is not an issue for solid lubrication. Single-walled nanotubes (SWNT) were modified by cutting into shorter segments and by fluorination. All SWNTs exhibited low CoF in air, with good wear lives. The SWNT with slight fluorination yielded an ultra-low CoF of 0.002 although the best wear life was attributed to the nascent SWNT.

\section{SUBJECT TERMS}

Lubrication

\section{NUMBER OF PAGES} 32

16. PRICE CODE

\section{SECURITY CLASSIFICATION OF REPORT \\ Unclassified \\ 18. SECURITY CLASSIFICATION OF THIS PAGE \\ Unclassified}

\section{SECURITY CLASSIFICATION OF ABSTRACT \\ Unclassified}



